\title{
Improved information about the vertical location and extent of monolayer clouds from POLDER3 measurements in the oxygen A-band
}

\author{
M. Desmons, N. Ferlay, F. Parol, L. Mcharek, and C. Vanbauce \\ Laboratoire d'Optique Atmosphérique, UFR de Physique, UMR8518/CNRS, Université Lille 1, Villeneuve d'Ascq, France \\ Correspondence to: M. Desmons (marine.desmons@ed.univ-lille1.fr)
}

Received: 1 February 2013 - Published in Atmos. Meas. Tech. Discuss.: 12 March 2013

Revised: 23 July 2013 - Accepted: 24 July 2013 - Published: 30 August 2013

\begin{abstract}
This paper describes new advances in the exploitation of oxygen A-band measurements from POLDER3 sensor onboard PARASOL, satellite platform within the ATrain. These developments result from not only an account of the dependence of POLDER oxygen parameters to cloud optical thickness $\tau$ and to the scene's geometrical conditions but also, and more importantly, from the finer understanding of the sensitivity of these parameters to cloud vertical extent. This sensitivity is made possible thanks to the multidirectional character of POLDER measurements. In the case of monolayer clouds that represent most of cloudy conditions, new oxygen parameters are obtained and calibrated from POLDER3 data colocalized with the measurements of the two active sensors of the A-Train: CALIOP/CALIPSO and CPR/CloudSat. From a parameterization that is $\left(\mu_{\mathrm{s}}, \tau\right)$ dependent, with $\mu_{\mathrm{s}}$ the cosine of the solar zenith angle, a cloud top oxygen pressure (CTOP) and a cloud middle oxygen pressure (CMOP) are obtained, which are estimates of actual cloud top and middle pressures (CTP and CMP). Performances of CTOP and CMOP are presented by class of clouds following the ISCCP classification. In 2008, the coefficient of the correlation between CMOP and CMP is 0.81 for cirrostratus, 0.79 for stratocumulus, 0.75 for deep convective clouds. The coefficient of the correlation between CTOP and CTP is $0.75,0.73$, and 0.79 for the same cloud types. The score obtained by CTOP, defined as the confidence in the retrieval for a particular range of inferred value and for a given error, is higher than the one of MODIS CTP estimate. Scores of CTOP are the highest for bin value of CTP superior in numbers. For liquid (ice) clouds and an error of $30 \mathrm{hPa}(50 \mathrm{hPa})$, the score of CTOP reaches $50 \%(70 \%)$.
\end{abstract}

From the difference between CTOP and CMOP, a first estimate of the cloud vertical extent $h$ is possible. A second estimate of $h$ comes from the correlation between the angular standard deviation of POLDER oxygen pressure $\sigma_{\mathrm{P}_{2}}$ and the cloud vertical extent. This correlation is studied in detail in the case of liquid clouds. It is shown to be spatially and temporally robust, except for clouds above land during winter months. The analysis of the correlation's dependence on the scene's characteristics leads to a parameterization providing $h$ from $\sigma_{\mathrm{O}_{2}}$. For liquid water clouds above ocean in 2008, the mean difference between the actual cloud vertical extent and the one retrieved from $\sigma_{P_{\mathrm{O}_{2}}}$ (from the pressure difference) is $5 \mathrm{~m}(-12 \mathrm{~m})$. The standard deviation of the mean difference is close to $1000 \mathrm{~m}$ for the two methods. POLDER estimates of the cloud geometrical thickness obtain a global score of $50 \%$ confidence for a relative error of $20 \%(40 \%)$ of the estimate for ice (liquid) clouds over ocean. These results need to be validated outside of the CALIPSO/CloudSat track.

\section{Introduction}

Cloud amount and the vertical distribution of cloud properties are key parameters of the climate system through their major influence on the incoming solar radiation and the outgoing thermal radiation. Heating and cooling rates within the atmosphere, fundamental drivers in the climate system (Stephens, 1978; Wang and Rossow, 1998), cannot be well estimated without a good description of the vertical cloudiness structure. Thus, among all the microphysical and 
macrophysical cloud properties, the cloud top pressure (CTP) and the cloud layer geometrical thickness $(h)$ represent very desired parameters to be retrieved. For climate studies those parameters must be provided on a global scale, and satellites are the most appropriate tool. Active sensors such as lidar (Winker and Trepte, 1998; Winker et al., 2007) or radar (Mace et al., 2009) have the inherent ability to provide the base and top altitudes of cloud layers, but they suffer from poor spatial coverage. It would be very interesting and valuable to get the same information from space instruments that have a large field of view like most passive instruments.

Different methods using passive measurements have been developed to infer the cloud top level from space. The most common one is the measurement of the brightness temperature at $11 \mu \mathrm{m}$ to obtain the cloud top temperature that is converted to the cloud top height (CTH) or cloud top pressure via a vertical atmospheric profile (Rossow and Schiffer, 1999). This method is well adapted to high opaque clouds but is known to be inappropriate in the case of temperature inversions. For example, the MODerate Resolution Imaging Spectroradiometer (MODIS) algorithm places the cloud above the inversion, which can lead to a cloud top mislocation of about $200 \mathrm{hPa}$ (Menzel et al., 2008). Another method used to retrieve CTP is the $\mathrm{CO}_{2}$-slicing technique (Wielicki and Coakley, 1981), that uses radiances measured within the $15 \mu \mathrm{m}$ $\mathrm{CO}_{2}$ absorption region. Because of the lack of sensitivity in the lower layers of the atmosphere, MODIS uses this method only for clouds whose tops are higher than $3 \mathrm{~km}$. For lower clouds the MODIS algorithm reverts to the $11 \mu \mathrm{m}$ brightness temperature method. Cloud top level can also be obtained from high spectral resolution infrared sounder instruments like the Atmospheric Infrared Sounder (AIRS) (Weisz et al., 2007). One advantage of the AIRS method is the ability to simultaneously retrieve CTP and the sounding profile. One can also mention methods that use stereo observations (Seiz et al., 2007; Wu et al., 2009) or the polarimetry of reflected sunlight (Goloub et al., 1994; Knibbe et al., 2000).

An alternative method to infer cloud top pressure is the exploitation of the absorption of solar radiation by the atmospheric dioxygen molecules. Dioxygen is well mixed in the atmosphere, and the depth of $\mathrm{O}_{2}$ absorption can be related to a certain atmospheric path length. Above a bright surface, as cloud acts in first approximation, $\mathrm{O}_{2}$ absorption that affects solar radiation backscattered toward a spaceborne sensor is mainly related to the scene vertical location (the cloud height in our case) and to the solar and viewing geometries. Such methods using reflected sunlight in oxygen-absorbing bands depend very weakly on the pressure/temperature vertical profiles. They do not suffer for a lack of sensitivity in the case of low clouds, and are not sensitive to temperature inversions. After several theoretical studies (Wu, 1985; Fischer and Grassl, 1991; Kuze and Chance, 1994), airborne experiments (Fischer et al., 1991) and satellite missions have provided measurements in the oxygen absorption A band, a spectral domain centered at $760 \mathrm{~nm}$ and approximately $15 \mathrm{~nm}$ width (see Fig. 1). Various studies have shown their capabilities to retrieve an apparent cloud pressure using different sensors with narrow bands centered on the oxygen absorption region (Vanbauce et al., 1998; Koelemeijer et al., 2001; Fournier et al., 2006; Lindstrot et al., 2006; Preusker et al., 2007; Lelli et al., 2012; Yang et al., 2013), with different spectral characteristics and different radiative inversion models.

As was stated in the earlier literature (Yamamoto and Wark, 1961; Saiedy et al., 1965), multiple scattering within cloud layers enhances absorption of radiation by dioxygen, and thus affects the relevance and accuracy of the retrieved cloud pressure from A-band measurements. It partly explains the difference between apparent and actual cloud top pressures, which has been largely recognized for the different measurement approaches described previously. It leads to a systematic overestimation of cloud top pressure (underestimation of cloud top height) (Vanbauce et al., 1998), and the apparent cloud pressure is actually close to the middle-ofcloud pressure (Vanbauce et al., 2003; Wang et al., 2008; Sneep et al., 2008; Ferlay et al., 2010). In the case of low cloud deck that evidently has a thin geometrical thickness, the bias is relatively small and the CTP can be fairly well determined, for example within $25 \mathrm{hPa}$ with MERIS $\mathrm{O}_{2}$ A-band technique (Lindstrot et al., 2006).

Referring to van de Hulst (1980), Ferlay et al. (2010) simulated photon transport and radiative transfer inside cloudy atmospheres, and showed that the vertical photon penetration into cloud layers depends mainly on the cloud geometrical thickness $h$, with an angular dependance, and so does the difference between POLDER cloud apparent pressure and actual cloud top pressure. They further analyzed that, thanks to the multiangular character of POLDER instrument, POLDER oxygen pressure products and $h$ are potentially strongly correlated. A first intensive intercomparison of cloud layer altitudes inferred from CPR/CALIOP collocated with POLDER measurements confirmed this correlation. Thus, the sensitivity of measurements in the oxygen A band to the unknown cloud geometrical thickness $h$ can be exploited in order to retrieve $h$ instead of being the most important source of errors when deriving the cloud top pressure (Preusker and Lindstrot, 2009). The present paper follows the study of Ferlay et al. (2010). Based on an enhanced understanding of the sensitivities of POLDER oxygen pressure and on an extended database, we show here how we can gain further information about cloud pressures and vertical extent.

This paper is organized as follows. In Sect., 2, the characteristics and principle of POLDER oxygen A-band measurements and pressure are reiterated, and the known bias and sensitivity of POLDER oxygen pressure products are presented. In Sect. 3, the other A-Train data used in this study are detailed, as are the statistics of the cloud population on which our study focuses. In Sect. 4, we explain the principle for getting estimates of cloud top and middle pressures and the associated results. In Sect. 5, the strength and 


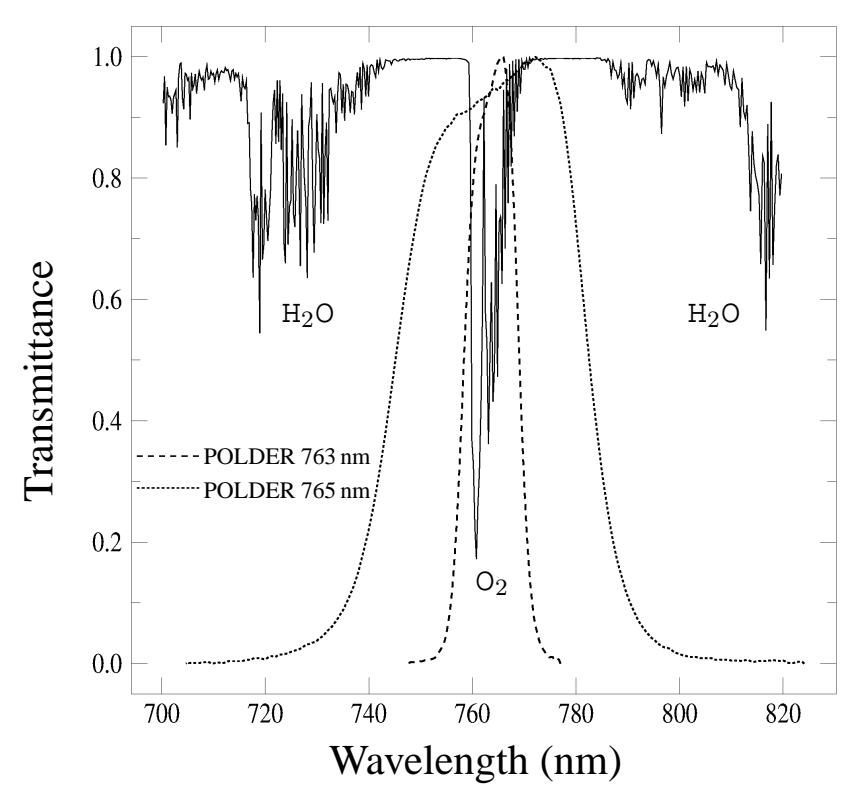

Fig. 1. Atmospheric transmittance in the oxygen A-band region at the resolution of $5 \mathrm{~cm}^{-1}$ ( $\simeq 0.3 \mathrm{~nm}$ ) for an air mass equal to 1 and a standard midlatitude summer atmosphere. The filter's transmissions of the two POLDER $\mathrm{O}_{2}$ bands (centered at $763 \mathrm{~nm}(765 \mathrm{~nm})$ with a $10 \mathrm{~nm}(40 \mathrm{~nm}) \mathrm{FWHM})$ are also given in dashed lines.

characteristics of the correlation between the angular standard deviation of POLDER oxygen pressure $\sigma_{\mathrm{P}_{2}}$ and the cloud geometrical thickness $h$ are studied. From this correlation and the new pressure estimates, the cloud geometrical thickness $h$ can be inferred in two ways. In Section 6, we compare the retrievals of $h$ obtained from the two methods.

\section{POLDER oxygen pressure}

\subsection{POLDER cloud oxygen pressure principle and algorithm}

In this study we use data obtained from measurements of the POLDER3 sensor onboard the PARASOL platform within the Afternoon satellite constellation (A-Train, Stephens et al. (2002)). PARASOL was launched in 2004. Its orbit was lowered for the first time in December 2009, and then again in November 2011. Since then, PARASOL has not performed as many measurements coincident with other A-Train satellites as previously, though the POLDER3 sensor still works perfectly.

POLDER cloud oxygen pressure is inferred from multidirectional measurements in two large spectral channels located in the oxygen A band, centered at around 763 and $765 \mathrm{~nm}$. Their values for full width at half maximum (FWHM) are respectively 10 and $40 \mathrm{~nm}$. Figure 1 illustrates the spectral variability of the atmospheric absorption in this domain as well as the POLDER response filters for the two channels.

The oxygen pressure algorithm is based upon the fact that $\mathrm{O}_{2}$ absorption indicates the penetration depth of radiation within the atmosphere. The oxygen transmittance $T_{\mathrm{O}_{2}}$ from the top of the atmosphere to a level pressure $P$ and then back to space is estimated by the ratio of POLDER radiances measured at 763 and $765 \mathrm{~nm} . T_{\mathrm{O}_{2}}$ was precalculated for various reflector pressure levels, geometrical conditions, and standard atmospheric models using a line-by-line model (Scott, 1974) and spectroscopic parameters from HITRAN 2004 (Rothman et al., 2005). An apparent cloud pressure is thus inferred with the hypothesis of the atmosphere being a purely absorbing medium, the cloud as a perfect reflector, and with reflectances at 763 and $765 \mathrm{~nm}$ corrected for gaseous absorption by water vapor and ozone. Details are given in Buriez et al. (1997).

With its CCD sensor array, POLDER acquires up to 14 quasi-simultaneous observations of the same elementary pixel $\left(6 \times 7 \mathrm{~km}^{2}\right)$ with different viewing geometries. In the level 2 POLDER operational algorithm, the cloud pressure value assigned to a super-pixel $\left(18 \times 21 \mathrm{~km}^{2}\right)$ is determined for each viewing direction from the spatial averaging of the results obtained for each elementary cloudy pixel with spherical albedo larger than 0.3 (which corresponds to an optical thickness equal to 2 for liquid water clouds and 3.5 for ice clouds). An additional correction is made over land surface to take into account the increase of the photon path length due to multiple scattering between the cloud and the surface (Vanbauce et al., 2003). The angular values are then averaged accounting for cloud fraction - the mean is denoted by $P_{\mathrm{O}_{2}}$ - and the associated angular standard deviation $\sigma_{\mathrm{P}_{2}}$ is calculated. For technical reasons as well as the question of cloud pressure accuracy, the averaged cloud pressure is finally rounded to the nearest $5 \mathrm{hPa}$ and the angular standard deviation to the nearest $2.5 \mathrm{hPa}$.

\subsection{Known bias and sensitivity to cloud vertical extent}

Real clouds do not act as perfect reflecting boundaries. Solar photons actually penetrate into the cloud layer before being backscattered toward space. Consequently, the photon path is increased as well as absorption by oxygen. Because this increase is not accounted for in the POLDER algorithm, a main feature of POLDER cloud oxygen pressure is that it is systematically higher than the cloud actual actual top pressure (CTP). Comparisons between POLDER apparent pressure and cloud top pressure derived from METEOSAT infrared measurements showed a mean difference of $180 \mathrm{hPa}$ (Vanbauce et al., 1998). Similar comparisons with the International Satellite Cloud Climatology Project (ISCCP) cloud top pressure showed a bias of $140 \mathrm{hPa}$ (Parol et al., 1999). More precisely, cloud oxygen pressure appears to be close to the pressure of the geometrical middle of cloud layer. This has been observed with SCIAMACHY data (Wang et al., 


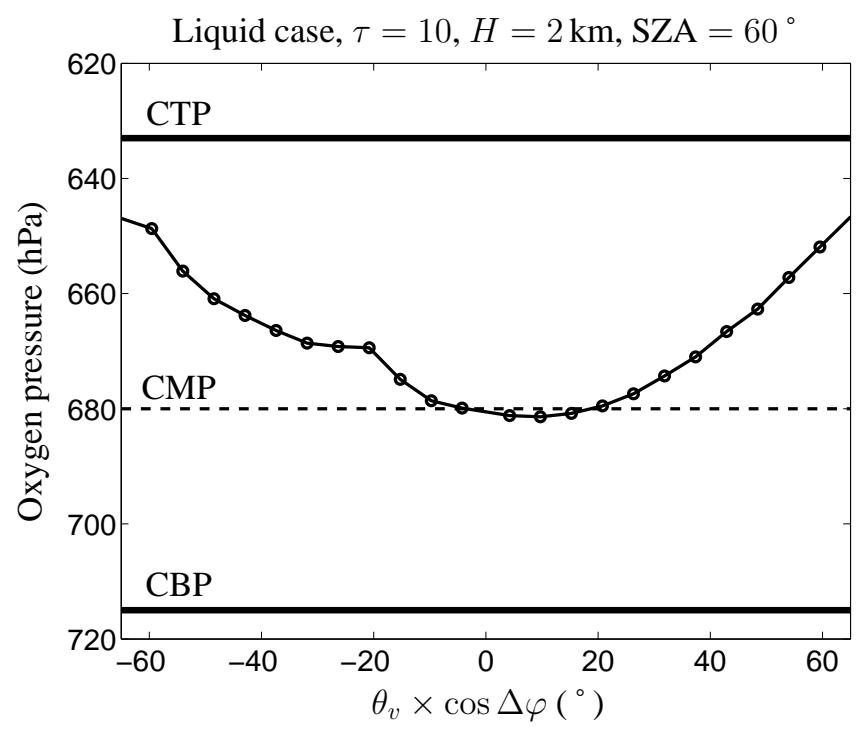

Fig. 2. Variation of simulated POLDER directional cloud oxygen pressure with the viewing zenith angles $\theta_{\mathrm{V}}$ in the solar plane ( $\Delta \varphi$ is the measurement's relative azimuth). Characteristics of the case study are indicated in the title. Horizontal lines indicate the level of cloud top, middle, and base pressures (denoted respectively by CTP, CMP, and CBP). The angularly averaged oxygen pressure is here $667 \mathrm{hPa}$ and the angular standard deviation $11 \mathrm{hPa}$. Discontinuities of the directional cloud oxygen pressure at $-60^{\circ}$ and $-20^{\circ}$ are signatures of cloud scattering phase function.

2008) and with POLDER data (Vanbauce et al., 2003; Sneep et al., 2008).

Ferlay et al. (2010) studied in detail the vertical photon penetration - denoted by $\langle Z\rangle-$ into the cloud layer. For clouds optically thick enough, their Monte Carlo radiative transfer simulations showed the strong dependence of $\langle Z\rangle$ on the cloud geometrical thickness $h$, with a weaker dependence on the cloud optical thickness $\tau$ and cloud microphysical properties. It confirmed the asymptotic relation $<Z>=\mu_{\mathrm{s}} \mu_{\mathrm{v}} h$ from van de Hulst (1980), with $\mu_{\mathrm{s}}$ and $\mu_{\mathrm{v}}$ the cosines of the solar and viewing zenith angles, respectively. Because POLDER directional oxygen pressures are affected by $\langle Z\rangle$, they depend accordingly on the cloud geometrical thickness and the scene's geometry. First, they vary with the upwelling outgoing directions, and the angularly averaged oxygen pressure is close to the cloud middle pressure. This is illustrated for one case in Fig. 2. Secondly, for clouds optically thick enough, the level of POLDER pressures varies with the cloud geometrical thickness $h$, and the angular standard deviation $\sigma_{\mathrm{P}_{2}}$ of POLDER pressures is potentially highly correlated with $h$. Using a large set of POLDER data coincident with the measurements of the CPR and CALIOP sensors onboard CloudSat and CALIPSO, Ferlay et al. (2010) confirmed the small bias between $P_{\mathrm{O}_{2}}$ and the cloud middle pressure (CMP) for monolayer clouds, and proposed a way to reduce it. They confirmed also, thanks to the sensitivity of $\sigma_{\mathrm{P}_{2}}$ to $h$, the possible inversion of $h$ from $\sigma_{P_{\mathrm{O}_{2}}}$ for optically thick enough clouds, i.e., the feasibility of retrieving cloud geometrical thickness from multidirectional measurements in the oxygen A band.

From the dependence of POLDER oxygen products on cloud geometrical thickness $h$, we can investigate further in order to improve the significance of the retrieved cloud pressure, and truly invert the geometrical thickness of cloud from POLDER oxygen product. To reach these goals, we need to further analyze the sensitivity of POLDER oxygen pressures and of the correlation $\left(\sigma_{P_{\mathrm{O}_{2}}}, h\right)$ to the scene's characteristics. This is the purpose of the following Sects. 4, 5, and 6.

\section{A-Train dataset used}

In the next section we present new inferences obtained from POLDER cloud oxygen pressure level 2 parameters $P_{\mathrm{O}_{2}}$ and $\sigma_{P_{\mathrm{O}_{2}}}$ : new cloud pressures, and an estimate of the cloud geometrical thickness. The dataset that was used for this study is presented in this section. POLDER level 2 data were sampled under the CloudSat/CALIPSO track in order to get "true" cloud vertical locations from the lidar and radar echoes. The CPR radar onboard CloudSat and the CALIOP lidar onboard CALIPSO do indeed have complementarity sensitivities to detect thin and thick scattering layers. This intercomparison filters daytime only CloudSat/CALIPSO data such as POLDER oxygen pressure parameters. CALTRACK level 2 data belong to the pixels nearest to the lidar shots sampled at $5 \mathrm{~km}$. They are delivered by the ICARE thematic center as ICARE Multi-Sensor products (web address: http://www. icare.univ-lille1.fr/). The horizontal resolution of POLDER level 2 data corresponds to the size of POLDER super-pixel $\left(18 \times 21 \mathrm{~km}^{2}\right)$. Level 2 CloudSat 2B_GEOPROF_LIDAR data have a horizontal resolution of $2.5 \times 1.4 \mathrm{~km}^{2}$, and they provide cloud base and top altitudes (LAYERBASE and LAYERTOP) of no more than five cloud layers $n$ in each atmospheric column. From these altitudes, we obtain cloud geometrical extent denoted by $H$, as well as cloud base, top, and middle pressures (denoted by CBP, CTP, and CMP, respectively). The conversion from altitude to pressure is performed thanks to a local conversion index that has been added to the CALTRACK_L2_2B_GEOPROF_LIDAR files. Pressures in the atmospheric column come from meteorological reanalyses (Bloom et al., 2005) produced by the NASA Global Modeling and Assimilation Office (GMAO), and are available with CALIPSO CAL_LID_L2_05kmCPro files. All the data used in this study are listed in Table 1. MODIS data are used as a reference or to further filter data.

To analyze the expected information contained in POLDER A-band measurements, we restricted our study to cloud covers closest to the homogeneous plane-parallel deck that is optically thick enough and whose thermodynamical phase is similar when identified by POLDER or MODIS. The first condition is set through the following data filtering: 
Table 1. Level 2 A-Train data (daytime only) used in this study collocated with lidar shots sampled at $5 \mathrm{~km}$.

\begin{tabular}{llll}
\hline Product & Dataset & $\begin{array}{l}\text { Horizontal } \\
\text { resolution }\end{array}$ & Sensor (satellite) \\
\hline & $\begin{array}{l}\text { Cloud oxygen pressure } P_{\mathrm{O}_{2}} \\
\text { Cloud oxygen pressure angular stan- } \\
\text { dard deviation } \sigma_{P_{\mathrm{O}_{2}}}\end{array}$ & & \\
& $\begin{array}{l}\text { Cloud cover cc } \\
\text { Cloud thermodynamical phase } \\
\text { Cloud optical thickness } \tau\end{array}$ & $18 \times 21 \mathrm{~km}^{2}$ & POLDER3 (PARASOL) \\
& $\begin{array}{l}\text { Cosine of the solar zenith angle } \mu_{\mathrm{S}} \\
\text { SBrface type index }\end{array}$ & & \\
& $\begin{array}{l}\text { Number of cloud layers } n \\
\text { Cloud top altitudes LAYERTOP } \\
\text { Cloud base altitudes LAYERBASE }\end{array}$ & $2.5 \times 1.4 \mathrm{~km}^{2}$ & $\begin{array}{l}\text { CPR/CALIOP } \\
\text { (CloudSat/CALIPSO) }\end{array}$ \\
\hline MYDO6_L2.C5 & $\begin{array}{l}\text { Cloud top pressure MODIS CTP } \\
\text { Cloud phase optical properties }\end{array}$ & $\begin{array}{l}5 \mathrm{~km} \\
1 \mathrm{~km}\end{array}$ & MODIS (Aqua) \\
\hline
\end{tabular}

clouds are monolayered $(n=1)$, and the cloud cover is close to unity (POLDER fractional cloud cover "cc" - at the resolution of $18 \times 21 \mathrm{~km}^{2}-$ is larger than 0.95$)$. However, it is obvious that ice clouds that have a large vertical extent of several kilometers are necessary more away from the model of the homogeneous plane-parallel slab. For the second condition we considered clouds with $\tau \geq 5$. Indeed, Ferlay et al. (2010) have shown that $\sigma_{P_{\mathrm{O}_{2}}}$ and the cloud vertical extent $H$ were correlated for liquid water clouds with $\tau \geq 5$ and for ice clouds with $\tau \geq 10$. After a study of the sensitivity of the correlation between $\sigma_{P_{O_{2}}}$ and $H$ to the cloud optical thickness, it appears that this correlation stays high for $\tau \geq 5$ whatever the thermodynamic phase.

This study focuses on the retrieval of parameters of singlelayer clouds. We give below some statistics in order to realize the importance and characteristics of this cloud population among all clouds. According to CPR and CALIOP measurements (2B-GEOPROF-LIDAR product), monolayer clouds represent $64 \%$ of cloud covers in 2008. But their occurrences vary with the latitude. It is shown in Fig. 3a with the plots of the zonal occurrences of monolayered and multilayered clouds as a function of the latitude by $5^{\circ}$ bins.

The occurrence of monolayered clouds are higher at latitudes larger than $20^{\circ}$ south and north, where it does not vary a lot, mostly between $65 \%$ and $70 \%$. It means that our study deals with most of the clouds outside of the tropics. In the tropics, the occurrence of monolayer clouds decreases significantly down to $45 \%$ to the benefit of multilayer clouds. Figure $3 \mathrm{~b}$ shows that among monolayered clouds, liquid clouds are dominant except for latitudes between $-5^{\circ}$ and $+15^{\circ}$. On average, $53 \%$ are liquid ones, while about $27 \%$ are ice clouds.

In the rest of the paper, data comparison and statistics will only concern monolayered cloud covers filtered as indicated above. Clouds for which the POLDER fractional cloud cover is higher than 0.95 represent $87 \%$, and clouds with optical thickness larger than 5 are $73 \%$ of the whole cloud overcast. Clouds that are at the same time monolayered, not fractional (cc $>0.95)$, and optically relatively thick $(\tau \geq 5)$ correspond to $47 \%$ of all the clouds detected in 2008 under the CloudSat/CALIPSO track. Figure 4 shows the CPR/CALIOP climatology of cloud top pressure CTP versus cloud vertical extent $H$ for these selected monolayered clouds in 2008. Figure $4 \mathrm{a}$ and $\mathrm{b}$ are for ice clouds over ocean and land, respectively, and Fig. 4c and d for liquid clouds over the same surfaces. Here, red colors mean high density of cases, and blue colors low density. A common feature to these plots is the correlation between lower cloud top pressure and higher vertical extent (with a bow shape for ice clouds), and the more scattered feature over land. Concerning ice clouds, the main difference between clouds over land and ocean in the CTP- $H$ diagram is the higher density of geometrically thinner (geometrical thicknesses between 2000 and $7000 \mathrm{~m}$ ) high-level clouds over land than over ocean. This is consistent with the climatologies obtained by Stubenrauch et al. (2006) and Warren et al. (2012). Concerning liquid clouds, Fig. 4c and $4 \mathrm{~d}$ show that there are more clouds at higher altitudes and that clouds are more extended vertically over land than over ocean. This observation is coherent with Stubenrauch et al. (2006) and Wang et al. (2000), and may be explained by the altitude of the land surface and the highest occurrence of lowlevel cloudiness over ocean.

\section{Definition of new POLDER oxygen pressures}

Thanks to their theoretical analysis of the vertical penetration of photons into the cloud layer, and some first statistical comparisons between POLDER oxygen pressure $P_{\mathrm{O}_{2}}$ and actual cloud pressure, Ferlay et al. (2010) obtained a better 


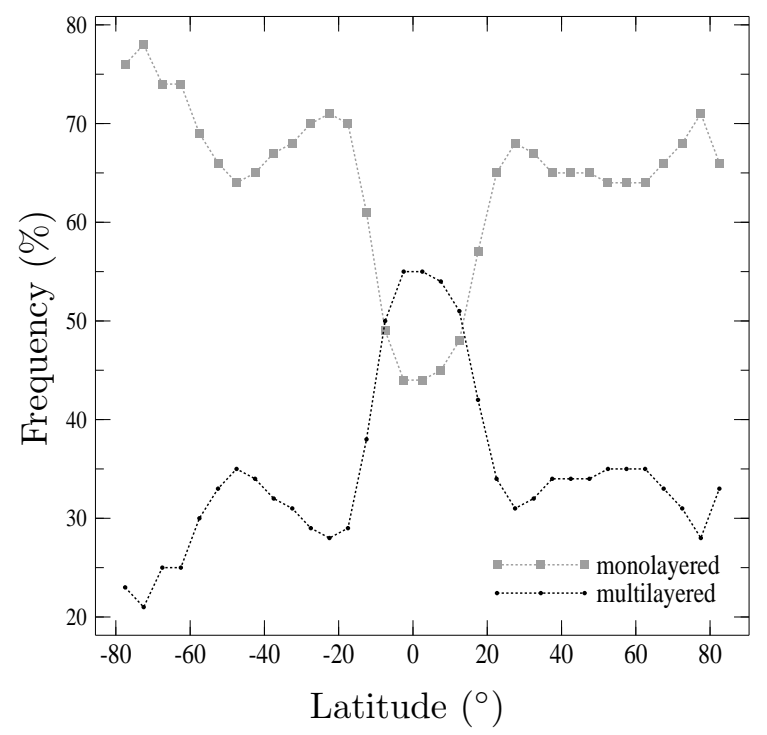

(a)

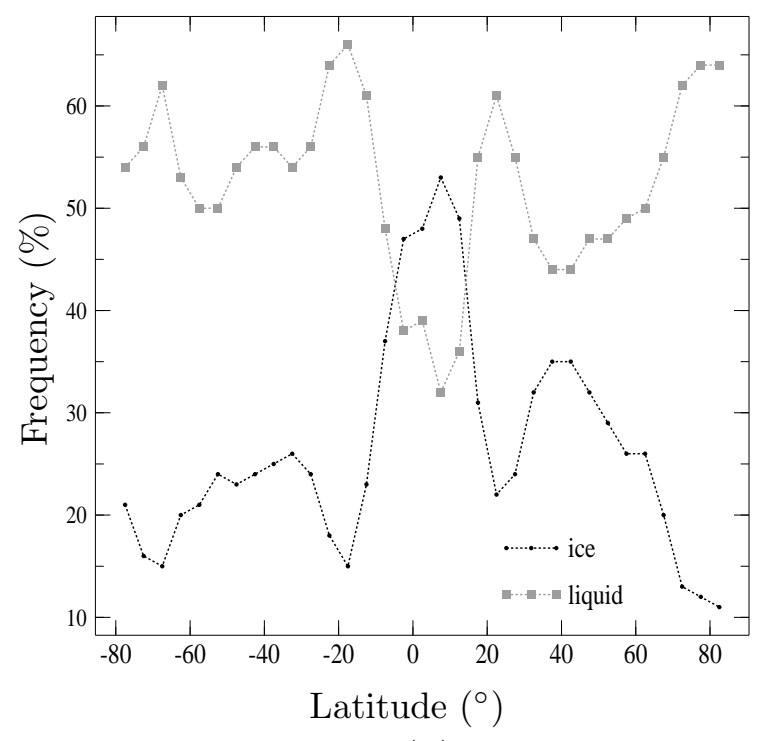

(b)

Fig. 3. Climatology of monolayered vs. multilayered clouds in 2008 from the 2 B-GEOPROF-LIDAR product. (a) provides the zonal occurrences in percent of monolayered (grey line) and multilayered (black line) clouds. (b) provides the zonal occurrences in \% of liquid water (grey line) and ice (black line) clouds among monolayered clouds (the thermodynamical phase comes from PARASOL and MODIS).

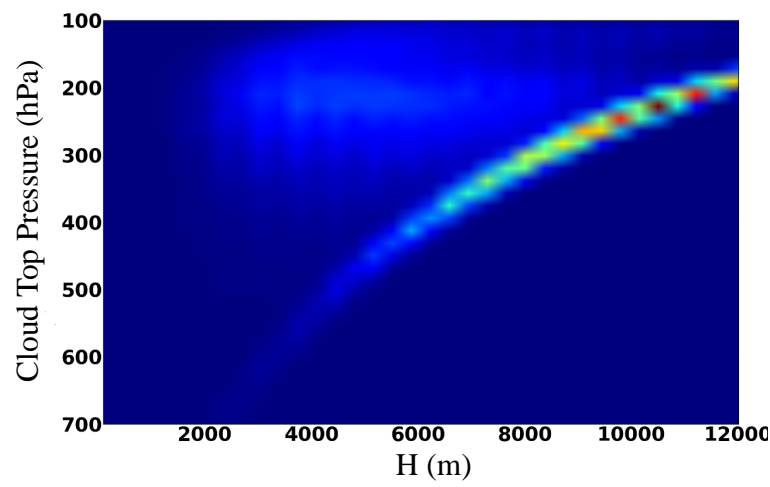

(a) Ice clouds over ocean

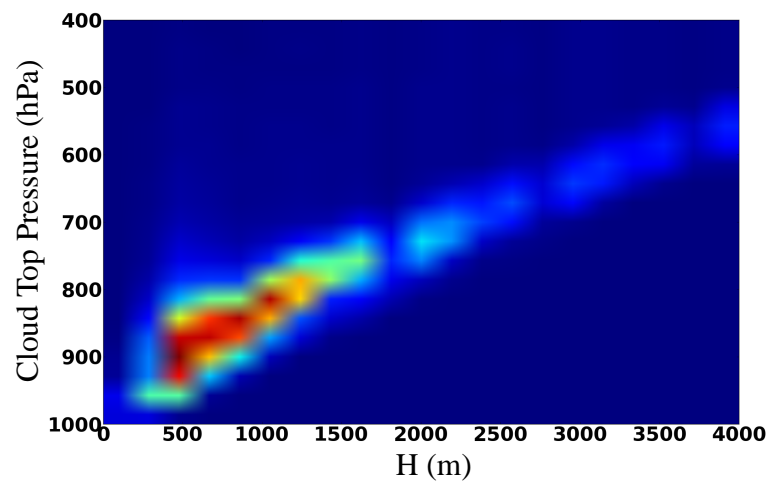

(c) Liquid clouds over ocean

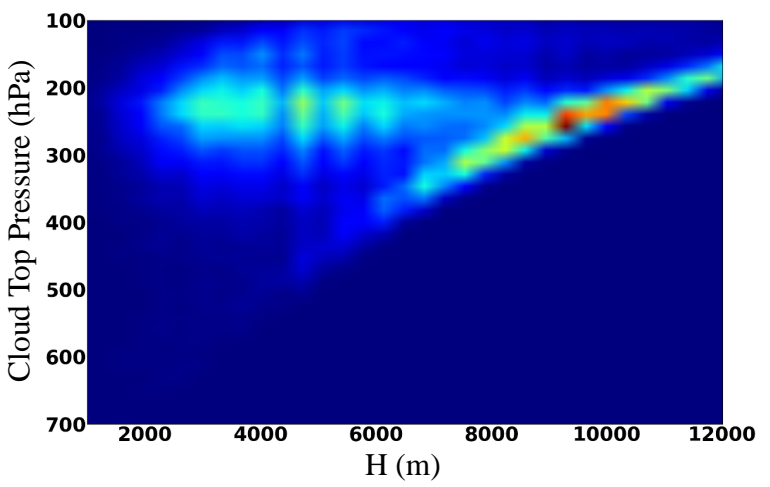

(b) Ice clouds over land

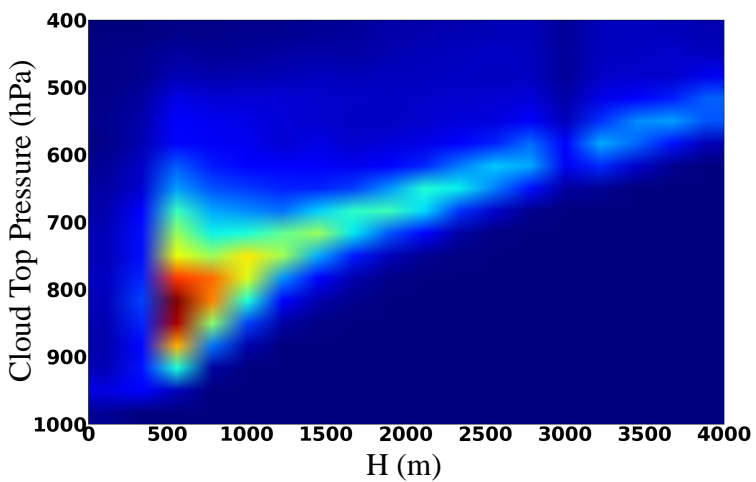

(d) Liquid clouds over land

Fig. 4. Climatology of cloud top pressure versus cloud vertical extent for selected monolayered clouds in 2008 based on the 2B-GEOPROFLIDAR product: over ocean on the left-hand panels, and over land on the right-hand panels. The thermodynamical phase comes from PARASOL and MODIS. 


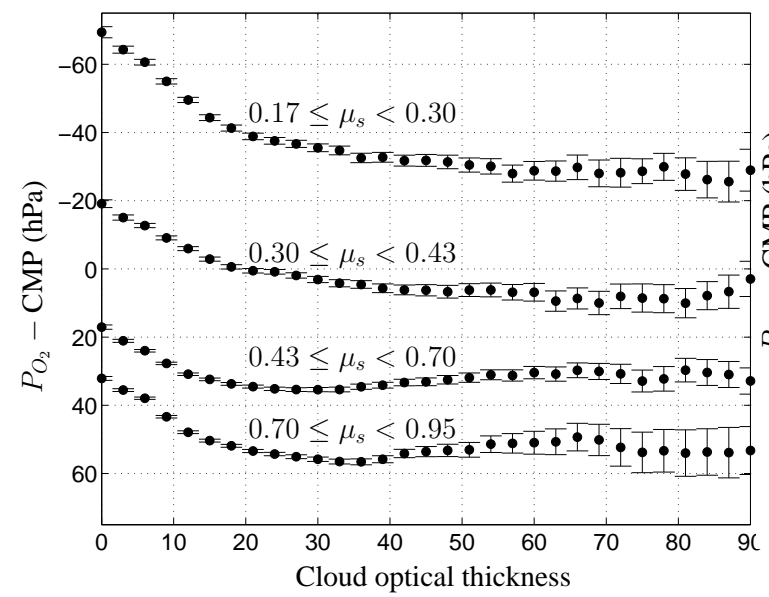

(a) For liquid water clouds

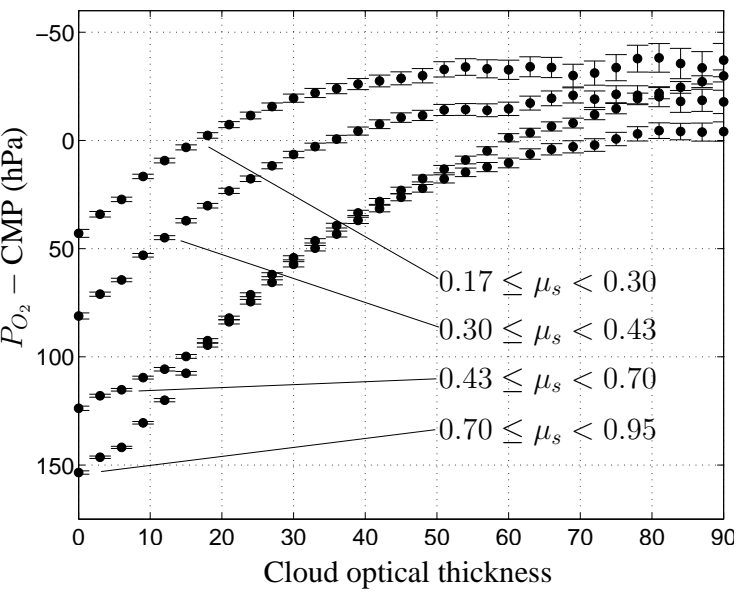

(b) For ice water clouds

Fig. 5. Difference between POLDER oxygen pressure and actual cloud middle pressure (CMP) from CPR/CALIOP as a function of cloud optical thickness, on average in 2008 and by classes of solar zenith angle's cosine. Standard deviations are indicated by error bars.

significance for the inferred oxygen pressures. Here, we follow on from this effort by accounting for the double dependence of cloud oxygen pressures to cloud optical thickness and solar zenith angle (or its cosine $\mu_{\mathrm{s}}$ ). We show that this leads to estimates of cloud middle and top pressures.

To evaluate the relevance of these pressures, we make use of the International Satellite Cloud Climatology Project (ISCCP) definitions (Rossow and Schiffer, 1999) to distinguish high clouds $(\mathrm{CTP}<440 \mathrm{hPa})$, midlevel clouds $(440 \mathrm{hPa}<$ $\mathrm{CTP}<680 \mathrm{hPa})$ and low clouds $(\mathrm{CTP}>680 \mathrm{hPa})$. High clouds can be further separated into cirrus $(\tau<3.6)$, cirrostratus $(3.6<\tau<23)$, and deep convective clouds $(\tau>$ $23)$. Midlevel clouds are separated into altocumulus $(\tau<$ 3.6), altostratus $(3.6<\tau<23)$, and nimbostratus $(\tau>23)$. Among low clouds, the distinction is made between cumulus $(\tau<3.6)$, stratocumulus $(3.6<\tau<23)$, and stratus $(\tau>23)$. In this study, only clouds with an optical thickness larger than 5 are considered, which excludes cirrus, altocumulus, and cumulus. Low and middle clouds are also classified according to their thermodynamical phase, while high clouds are all iced.

\subsection{Estimate of cloud middle pressure: principle and results}

Ferlay et al. (2010) studied the difference between $P_{\mathrm{O}_{2}}$ and the pressure of the cloud's midlevel (CMP). Here we continue to make the distinction between liquid and ice clouds, and we go further by accounting for the dependence, not only on cloud optical thickness but also on the solar zenith angle. Figure 5 shows the difference on average between POLDER oxygen pressures and actual cloud middle pressure (CMP) obtained from CPR/CALIOP for liquid clouds (Fig. 5a) and ice clouds (Fig. 5b).
It shows that the higher the sun, the higher the POLDER oxygen pressure $P_{\mathrm{O}_{2}}$ compared with CMP. This is because the pathlength of photons within cloud layers is enhanced when the sun is high, or equivalently that they penetrate further into the clouds. Figure 5 shows also the sensitivity of the pressure's difference to cloud optical thickness $\tau$. This sensitivity is low for liquid clouds, while high for ice clouds. For liquid clouds on average, $P_{\mathrm{O}_{2}}-$ CMP does not depend much on cloud optical thickness for $\tau \geq 20$. For ice clouds, the absolute value of $P_{\mathrm{O}_{2}}-\mathrm{CMP}$ is smaller than $50 \mathrm{hPa}$ when $\tau \geq 40$, and much larger for lower values of $\tau$.

The principle for obtaining an estimate of CMP from POLDER oxygen pressure $P_{\mathrm{O}_{2}}$ is the following: if $P_{\mathrm{O}_{2}}-\mathrm{CMP}=f\left(\tau, \mu_{\mathrm{s}}\right)$, then $P_{\mathrm{O}_{2}}-f\left(\tau, \mu_{\mathrm{s}}\right)$ should provide an estimate of CMP. Hereafter, we denote by CMOP the quantity $P_{\mathrm{O}_{2}}-f\left(\tau, \mu_{\mathrm{S}}\right)$, which stands for cloud middle oxygen pressure. We obtained CMOP after a fit of the functions shown in Fig. 5 with third-order polynomials.

Figure 6 shows the comparison between CMOP and CPR/CALIOP CMP for the four most numerous ISCCP cases in 2008. CMOP was obtained from a parameterization based on 2008 data. The color scale is not specified, but blue means the lowest density of points, and red the highest. Correlations for the years 2007 and 2009-2010 are close to the ones shown here. Also not shown is the comparison for stratus liquid clouds, for which the correlation is around 0.747 . The best comparison is obtained for ice clouds with high correlation and small bias, and the regression's slope close to unity. Comparisons for liquid low-level clouds show a larger bias, which might be due to the effect of Rayleigh scattering above the cloud layers. The result is worse for midlevel clouds, with a correlation of 0.54 . 


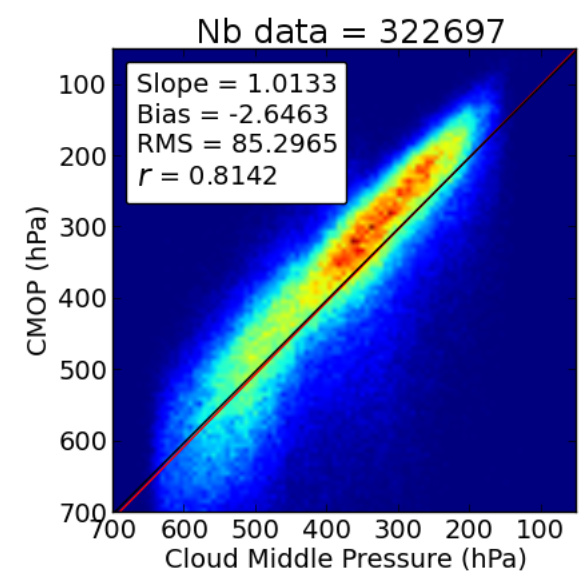

(a) Cirrostratus ice clouds

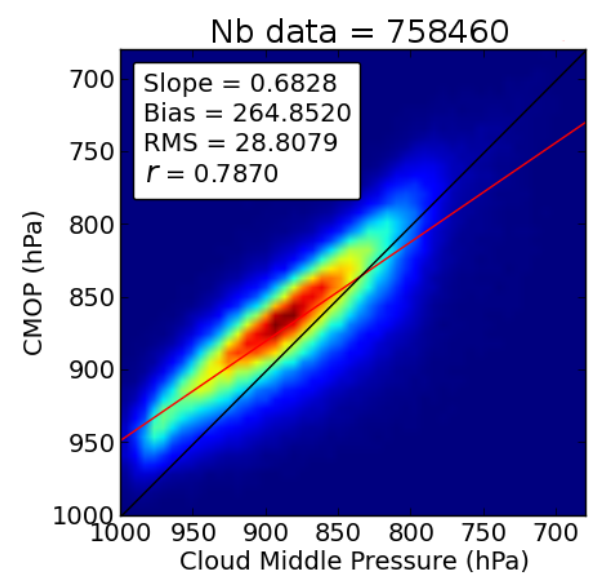

(c) Stratocumulus liquid water clouds

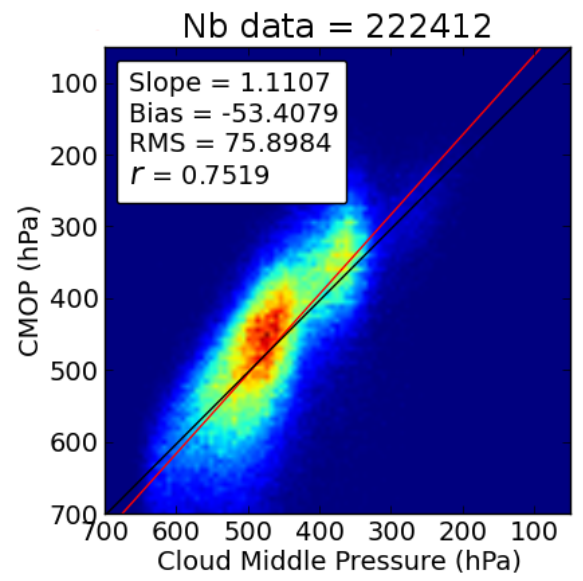

(b) Deep convective ice clouds

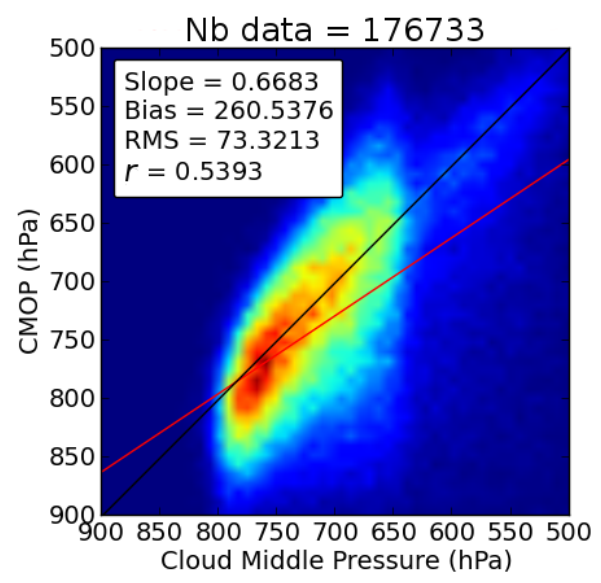

(d) Altostratus liquid water clouds

Fig. 6. Evaluation of POLDER cloud middle oxygen pressure (CMOP) versus CPR/CALIOP cloud middle pressure (in abscissa). Cases over ocean in 2008. Black lines indicate the one-to-one relationship, while red lines indicate the linear regression between CMOP and CMP.

\subsection{Estimate of cloud top pressure: principle and results}

It was mentioned earlier that the difference between $P_{\mathrm{O}_{2}}$ and the actual cloud top pressure CTP is mainly a function of the cloud geometrical thickness $h$. Additionally, $\sigma_{P_{\mathrm{O}}}$ is potentially strongly correlated with $h$ as shown by Ferlay et al. (2010) and as will be studied in detail in Sect. 5. Thus, as $P_{\mathrm{O}_{2}}-$ CTP depends on $h, P_{\mathrm{O}_{2}}-$ CTP depends on $\sigma_{P_{\mathrm{O}_{2}}}$. We considered obtaining an estimate of CTP by using this least dependence. If indeed $P_{\mathrm{O}_{2}}-\mathrm{CTP}=f\left(\sigma_{\mathrm{P}_{2}}\right)$, then $P_{\mathrm{O}_{2}}-f\left(\sigma_{\mathrm{P}_{2}}\right)$ should provide an estimate of CTP: we would unbias $P_{\mathrm{O}_{2}}$ with a parameterization that depends on an "observable", $\sigma_{\mathrm{O}_{2}}$. Hereafter, we denote by CTOP the quantity $P_{\mathrm{O}_{2}}-f\left(\sigma_{\mathrm{P}_{2}}\right)$, which stands for cloud top oxygen pressure. Figure 7 shows an example of functions $f\left(\sigma_{\mathrm{P}_{2}}\right)$ for the case of liquid clouds over ocean in 2008 and for solar zenith angles such that $0.7 \leq \mu_{\mathrm{s}} \leq 0.8$.

Not surprisingly, the difference $P_{\mathrm{O}_{2}}-$ CTP increases with $\sigma_{P_{\mathrm{O}_{2}}}$ : as clouds move away from the asymptotic model of a perfect reflector (for which $\sigma_{\mathrm{P}_{2}}$ would equal zero), $P_{\mathrm{O}_{2}}$ becomes larger than CTP. We obtained CTOP after a thirdorder polynomial fit of the functions $f\left(\sigma_{P_{\mathrm{O}_{2}}}\right)$ like the ones shown in Fig. 7. To evaluate the relevance of the new pressure CTOP, we classify again liquid and ice clouds according to the ISCCP cloud types. The right-hand panels of Fig. 8 show the comparison between CTOP and CPR/CALIOP CTP for the four most numerous ISCCP cases in 2008. CTOP was obtained from a parameterization based on data in 2008 . The center panels show, for comparison, the relation between POLDER cloud pressure $P_{\mathrm{O}_{2}}$ and CTP. The left-hand panels show for reference the relation between MODIS CTP and CTP.

Correlations obtained for the years 2007 and 2009-2010 are again close to the ones shown here. Figure 8 shows a decrease of the bias - from POLDER pressures $P_{\mathrm{O}_{2}}$ to CTOP - compared with CTP, which can be spectacular for clouds with a high vertical extent (cases a, b, and c). In the case of 


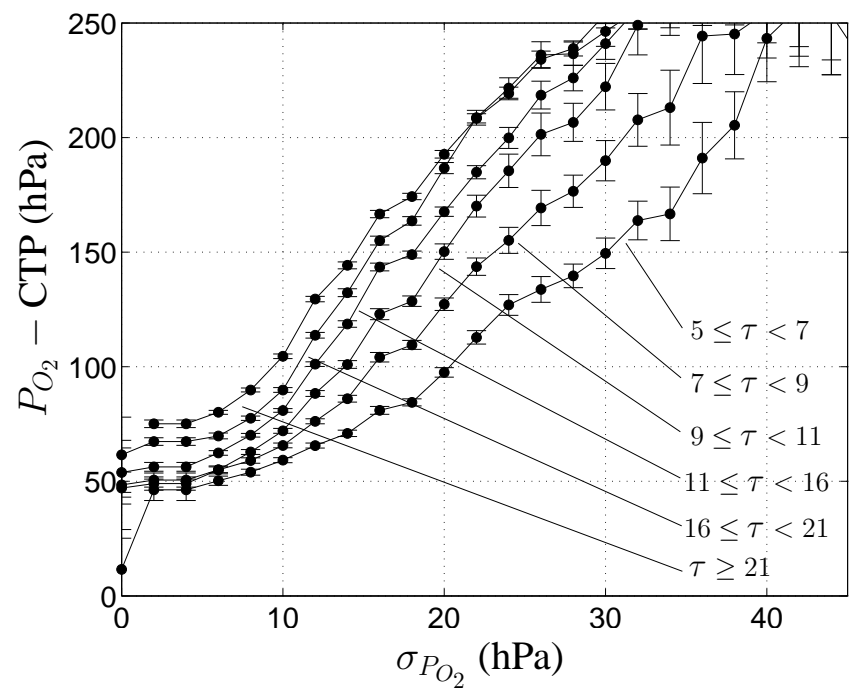

Fig. 7. Relationship between $P_{\mathrm{O}_{2}}-\mathrm{CTP}$ (the difference between POLDER oxygen pressure and CPR/CALIOP cloud top pressure) and the angular standard deviation of POLDER oxygen pressure $\sigma_{P_{\mathrm{O}_{2}}}$, on average in 2008 and for different classes of optical thickness $\tau$. Case of liquid water clouds over ocean, and for a particular solar condition: $0.7 \leq \mu_{\mathrm{s}} \leq 0.8$. Standard deviations are also shown with error bars.

liquid altostratus clouds (case c), the feature of the 2-D plot for CTOP and MODIS CTP (right- and left-hand panels, respectively) is quite different. This is due to the fact that numerous clouds with actual CTP $<580 \mathrm{hPa}$ come with biased new oxygen inference with CTOP $>600 \mathrm{hPa}$. For low-level liquid clouds (case d), the new POLDER pressure CTOP is again statistically closer to CTP than $P_{\mathrm{O}_{2}}$. A bias still exists, however, which might be due again to the effect of Rayleigh scattering above the cloud layers. For this last case, CTOP seems more relevant than Collection 5 MODIS CTP, whose known issue (Holz et al., 2008) is obvious on the left-hand panel of Fig. 8, case d.

To go further in the evaluation of the new POLDER pressure CTOP, we computed its score. We defined it as the occurrence of CTOP less than a given value away from the actual cloud top pressure given by CPR/CALIOP. The score corresponds thus to the confidence in the cloud top pressure retrieval for a given accuracy. The left-hand panels in Fig. 9 show such scores over ocean surface for different classes of CTP. Histograms of CTP are given in arbitrary units in order to visualize the distribution of CTP. For liquid water clouds (case a), scores on the left correspond to a distance of $30 \mathrm{hPa}$. For ice clouds (case b), the distance considered is $50 \mathrm{hPa}$. It should be noticed that scores of CTOP are the highest at the peak of the histogram. This is logical since CTOP is obtained from a statistical parameterization. For liquid clouds, the score obtained by CTOP is slightly higher than the one of MODIS CTP for pressures smaller than $600 \mathrm{hPa}$, but for most cases, the score of CTOP is much better, reaching $50 \%$ for pressures close to $850 \mathrm{hPa}$ (most case), and even $65 \%$ for clouds with pressure around $950 \mathrm{hPa}$, compared to $35 \%$ maximum for MODIS CTP. The global scores for all classes of CTP, shown on the right-hand panel of Fig. 9a, are better for CTOP than for MODIS CTP, regardless of the error given (for example, $45 \%$ compared to $25 \%$ for a $30 \mathrm{hPa}$ difference, $65 \%$ compared to $40 \%$ for $50 \mathrm{hPa}$ ). This confirms again the issue with the cloud top pressure inference by MODIS for low-level clouds. For ice clouds and an error of $50 \mathrm{hPa}$ (case b, left-hand panel), scores obtained by MODIS CTP are significantly higher than the one of CTOP when pressures are smaller than $200 \mathrm{hPa}$. Otherwise, scores of MODIS CTP and CTOP are close, with scores of CTOP slightly better, especially at low altitudes. The global scores for ice clouds - case b on the right - are slightly better for CTOP than for MODIS CTP, especially for errors less than $80 \mathrm{hPa}$ (for example, $48 \%$ compared to $38 \%$ for a $40 \mathrm{hPa}$ difference).

Above land, correlations - not shown here - between CTOP and CTP, and CMOP and CMP, do not change very much. The correlations tend to be slightly lower above land for most cases. It can be understood because of the surface effect, even if this effect is accounted for in the POLDER oxygen pressure algorithm. However, correlations above land are higher for low-level liquid clouds (between 0.04 and 0.07 higher). These higher correlations can be explained by the fact that the ranges of CMP and CTP values are larger above land compared with ocean. But the number of cases above land is 10 times smaller compared with ocean, which limits the comparison.

To summarize, we obtained new pressures - CMOP and CTOP - which are estimates of actual cloud middle and top pressures in the case of monolayer liquid and ice clouds. Comparison of scores are given for the estimates of CTP. From the difference between these two new pressures, we shall obtain a first estimate of the cloud vertical extent $h$. In Sect. 6, we evaluate the quality of this estimate of $h$. We shall see that the biases of CMOP and CTOP will compensate while calculating the estimate of $h$ from their difference between CMOP and CTOP for liquid clouds over ocean, but less over land.

\section{Correlation between $\sigma_{P_{\mathrm{O}_{2}}}$ and the cloud vertical extent}

As recalled in Sect. 2.2, the angular standard deviation $\sigma_{P_{\mathrm{O}_{2}}}$ of POLDER oxygen pressure is sensitive to the cloud geometrical thickness $h$, and consequently there is a potential to retrieve $h$ from $\sigma_{P_{\mathrm{O}_{2}}}$ for optically thick enough clouds. Ferlay et al. (2010) showed this potential for liquid water clouds from simulations and measurements. In this section, we go further and show the strength of the correlation between $\sigma_{\mathrm{P}_{2}}$ and CPR/CALIOP $H$ with a spatial and temporal study of the relation $H-\sigma_{\mathrm{O}_{2}}$. We also study the complex sensitivity 

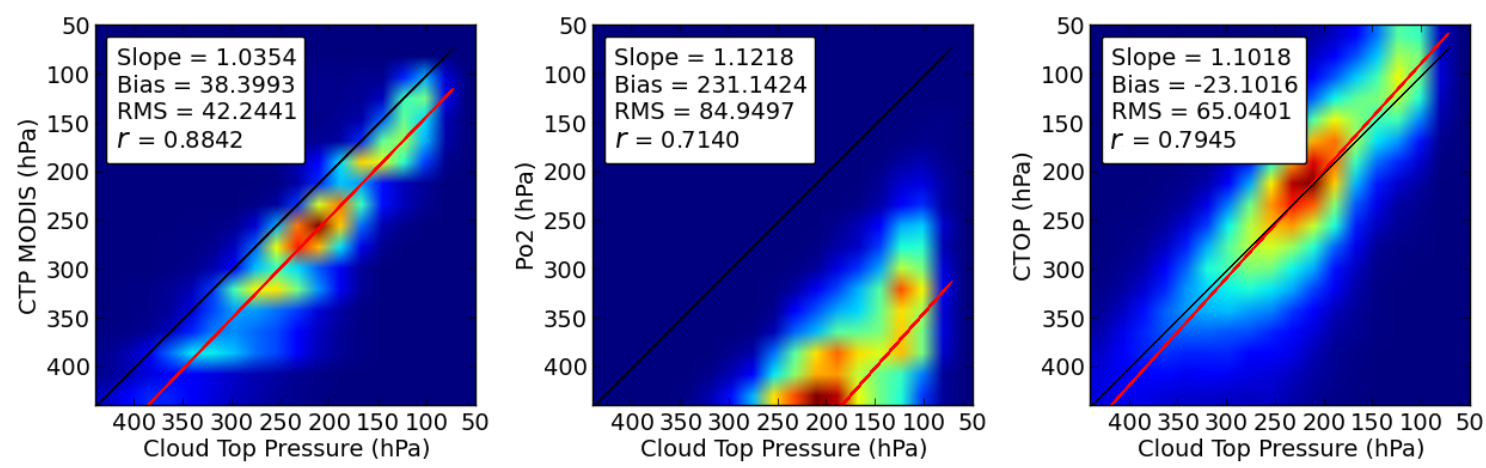

(a) For deep convective clouds $(\mathrm{Nb}$ data $=222412)$
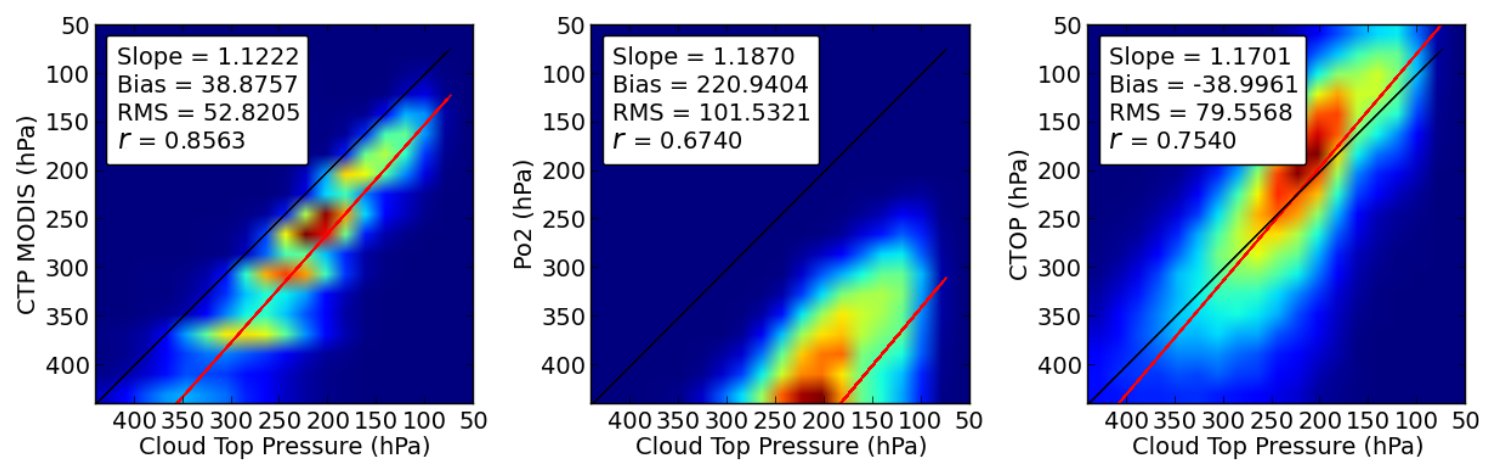

(b) For cirrostratus $(\mathrm{Nb}$ data $=282988)$
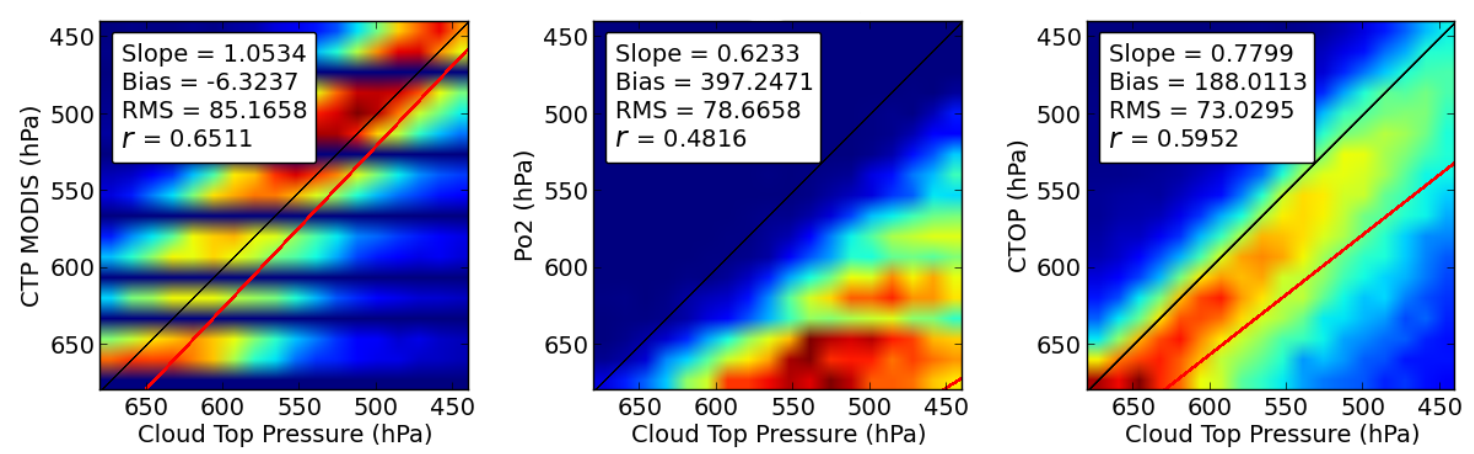

(c) For liquid altostratus $(\mathrm{Nb}$ data $=161498)$
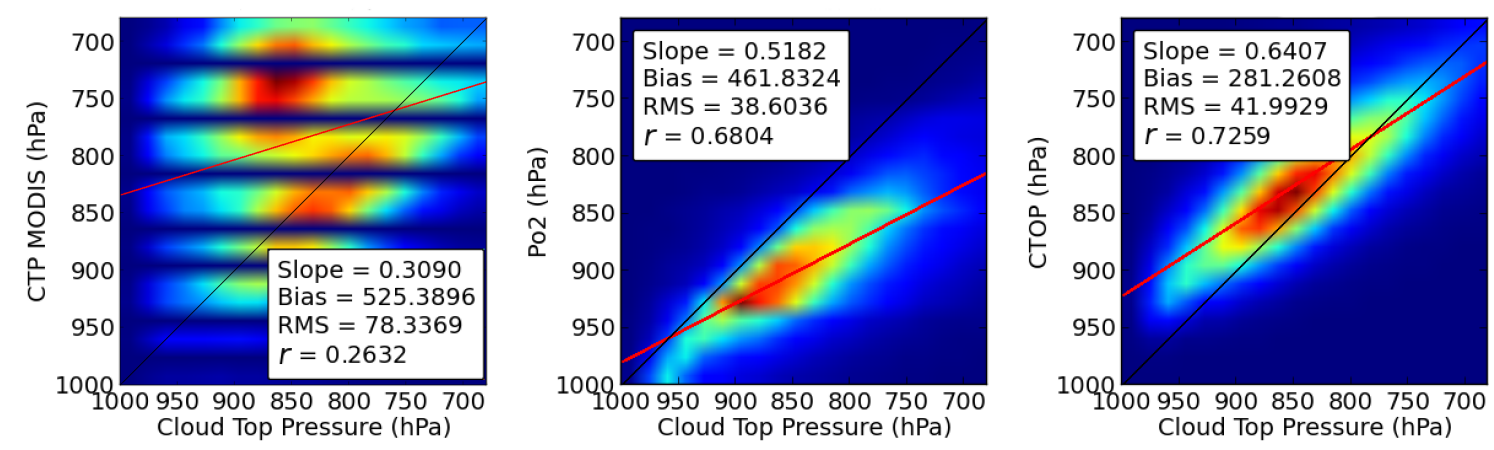

(d) For stratocumulus $(\mathrm{Nb}$ data $=666055)$

Fig. 8. Evaluation of MODIS cloud top pressure (CTP MODIS, left-hand panels), POLDER cloud oxygen pressure $\left(P_{\mathrm{O}_{2}}\right.$, middle panels) and cloud top oxygen pressure (CTOP, right-hand panels), versus CPR/CALIOP cloud top pressure (in abscissa). Cases over ocean in 2008. The number of data, $\mathrm{Nb}$ data, is given for each cloud type. Stripes in left-hand panels come from the very discrete values taken by MODIS CTP. 

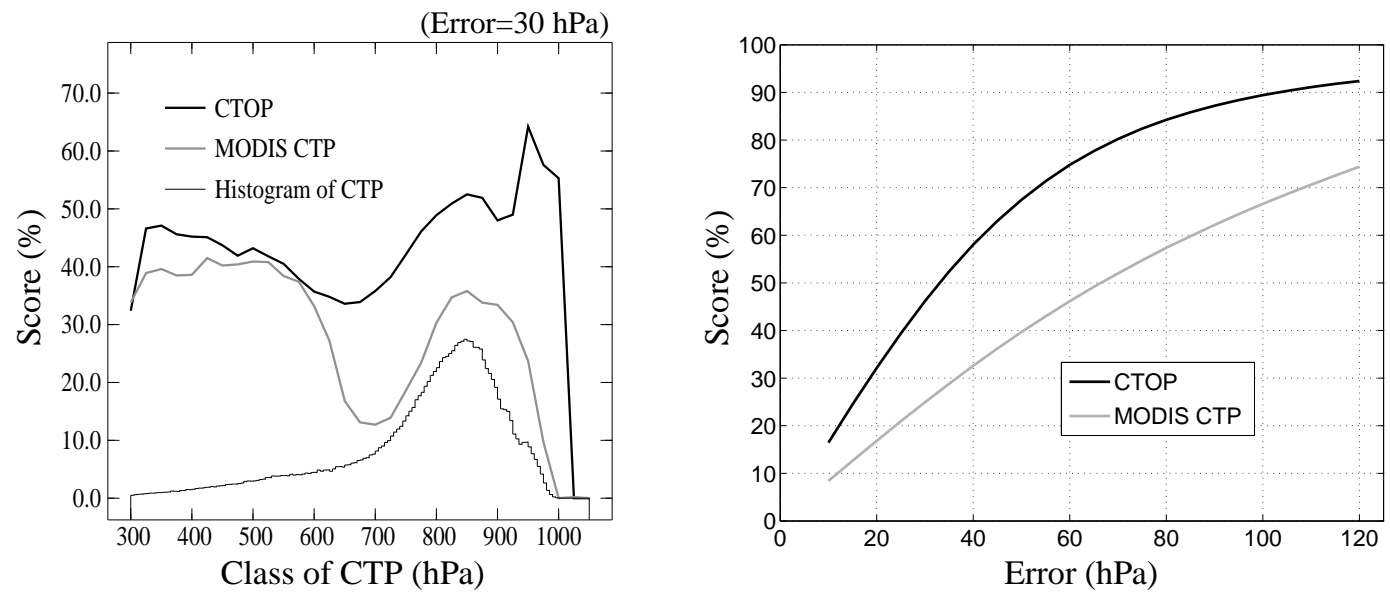

(a) Case of liquid water clouds
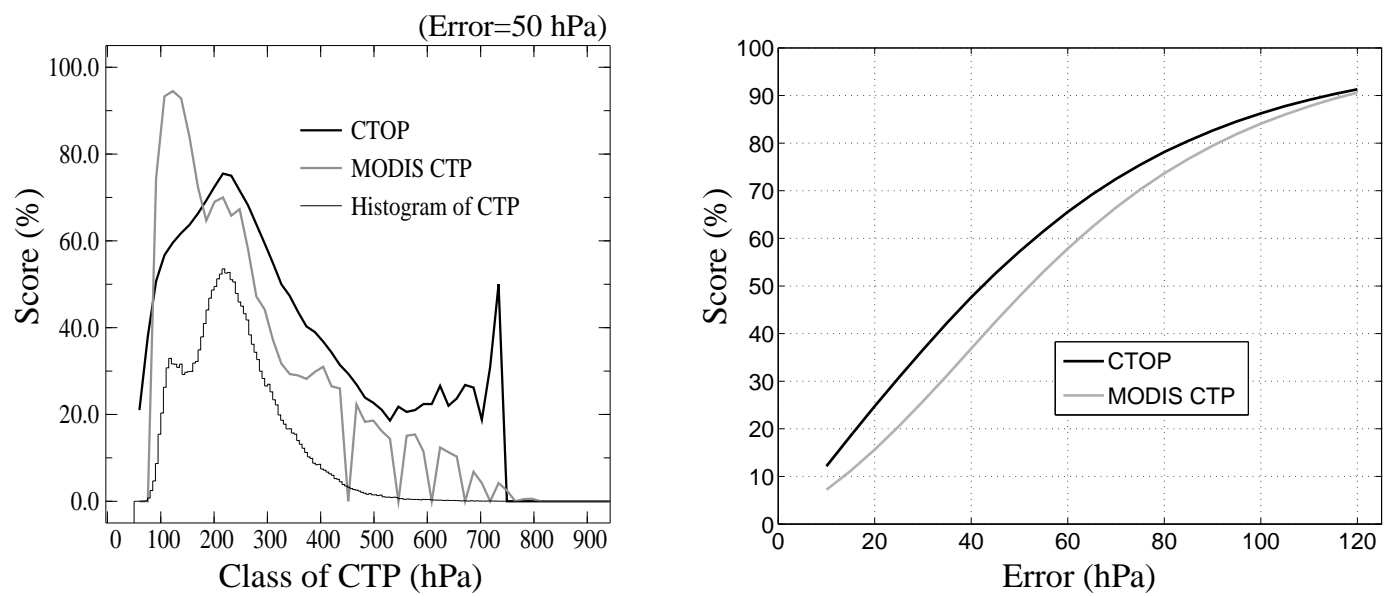

(b) Case of ice clouds

Fig. 9. Scores obtained in 2008 by the cloud top pressure estimates CTOP and MODIS CTP for liquid water (case a) and ice clouds (case b) over ocean. Scores correspond to a confidence in the retrieval for a given error. In the left-hand panels, scores are given per class of CTP, and for an error of $30 \mathrm{hPa}(50 \mathrm{hPa})$ for liquid (ice) clouds. In the right-hand panels, scores are global (all classes of CTP) and are given for different error values. Thick black lines are for CTOP; thick grey for MODIS CTP. Histograms of CTP are also plotted in left-hand panels (thin black lines, in arbitrary units).

of the relation between $H$ and $\sigma_{P_{\mathrm{O}_{2}}}$ to the cloud's optical thickness and to the viewing angle. The detailed study of this sensitivity will lead to an improved retrieval of $h$ from $\sigma_{\mathrm{P}_{2}}$. While the correlation exists also theoretically in the case of ice clouds, we show here results for liquid clouds only as the correlation observed between $H$ and $\sigma_{P_{\mathrm{O}_{2}}}$ is not straightforward for ice clouds. This is certainly due to their more complex microphysics, as well as their enhanced heterogeneities along thousands of vertical meters.

\subsection{Spatial variability of the correlation}

In a first step, we study the spatial variability of the correlation between $\sigma_{\mathrm{P}_{2}}$ and CPR/CALIOP $H$ at the global scale. To realize that, data are sorted by bin intervals of $10^{\circ}$ of latitude, $20^{\circ}$ of longitude, and $1 \mathrm{~km}$ width of geometrical thickness. These widths of interval allow for a correct statistical study of the regional correlation. Then, for each area and for each geometrical thickness class, the average and the standard deviation of $\sigma_{\mathrm{P}_{2}}$ are calculated. Finally, these two quantities are used in the pearsn routine (Press et al., 1992), which provides for each area the correlation coefficient $r$ and the slope $S$ of the linear regression between $\sigma_{\mathrm{P}_{2}}$ and the center of each geometrical thickness bin. Figure 10a shows the distribution of the correlation $r$ above ocean and land in 2008 for monolayer liquid clouds. The correlation coefficient is high for most areas in both hemispheres: $r$ is higher than 0.8 for 162 over 283 cases. The correlation coefficient can be, however, very low in several areas, in particular over land, over the Asian continent and Australia, and for very high latitudes. To synthesize, the correlation between $\sigma_{\mathrm{P}_{2}}$ and $H$ for liquid clouds is high for most meshes over ocean, and for 


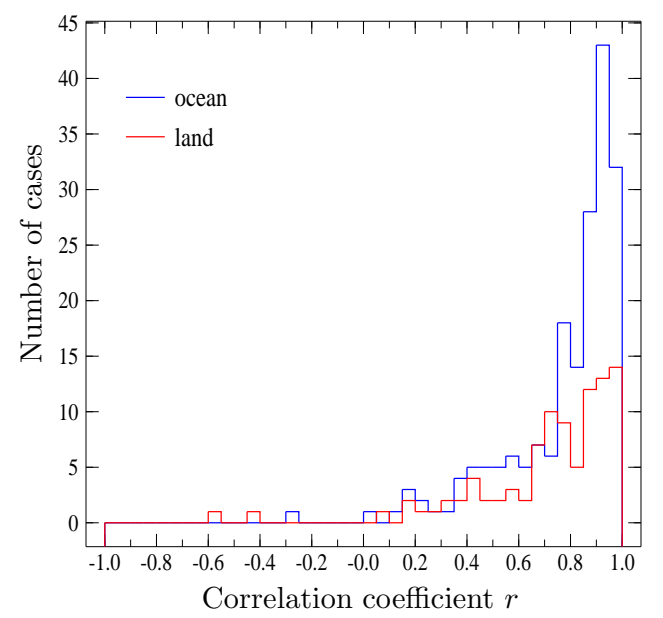

(a) Correlation coefficients at regional scale in 2008

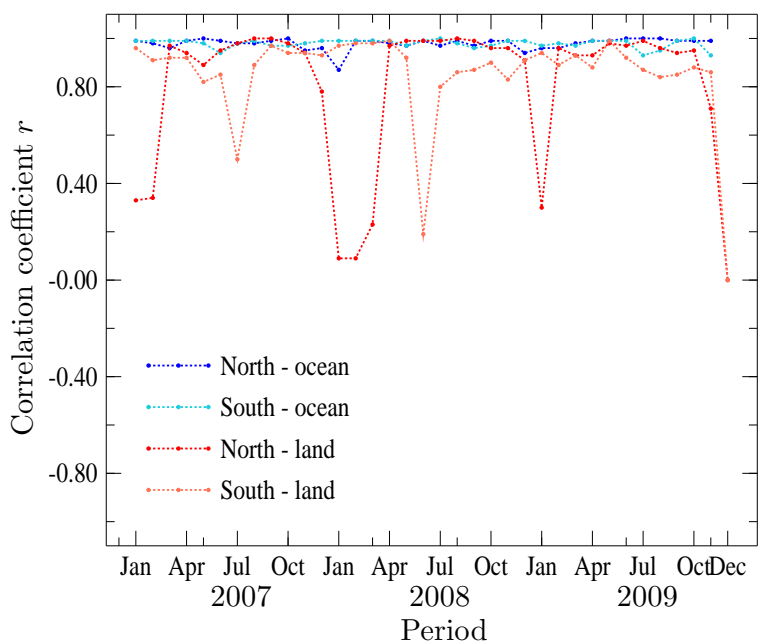

(b) Temporal evolution of the correlation coefficient

Fig. 10. Spatial variability (a) and temporal evolution (b) of the correlation coefficient $r$ between $\sigma_{P_{\mathrm{O}_{2}}}$ and CPR/CALIOP $H$. In (a), $r$ is calculated at regional scale (bins of $10^{\circ}$ of latitude and $20^{\circ}$ of longitude), distinguishing areas above ocean from areas above land in 2008. In (b), $r$ is calculated at synoptic scale month by month from 2007 to 2009 . Cases of monolayered liquid clouds with $\tau \geq 5$ and $c c \geq 0.95$.

half of the cases over land. This figure underlines the importance of distinguishing ocean from land for following studies. While not shown here, correlation coefficients for monolayered ice clouds have been calculated; however, the correlation is globally low: $r$ is higher than 0.8 only for 46 over 277 regions for which it was defined (in some areas, as for high latitudes, there were not enough clouds corresponding to our criteria to calculate the correlation coefficient). This is the reason why the present section focuses only on liquid water clouds.

\subsection{Temporal variability of the correlation}

In a second step, we study the temporal variability of the relation between $\sigma_{P_{2}}$ and CPR/CALIOP $H$. For three years of data (2007 to 2009), we calculated the monthly mean correlation coefficient $r$ with the same procedure as previously explained, and the slope $S$ of the linear regression between $\sigma_{\mathrm{P}_{2}}$ and $H$ when $r>0.8$. Figure $10 \mathrm{~b}$ shows the temporal evolution of the correlation $r$ for monolayered liquid clouds over the period 2007-2009, while distinguishing ocean from land in each hemisphere. This figure demonstrates that the correlation is temporally robust over ocean throughout the years. It also shows that the correlation stays high over land surfaces except in the winter months of each hemisphere. This decreasing of the correlation can be explained by the effect of brighter land surfaces not well accounted for by the POLDER algorithm, and the smaller number of liquid cloud cases over land in winter. It can explain the weak correlation that we observe over land in Fig. 10a, particularly at high latitudes. Slopes of the linear regression between $\sigma_{P_{\mathrm{O}_{2}}}$ and $H$ are on average around $3 \mathrm{hPa} \mathrm{km}^{-1}$, with a weak temporal variability over ocean and a higher one over land. This higher temporal variability can be explained by the stronger interannual variability of clouds over land than over ocean (Stubenrauch et al., 2006). These temporal variations in the slope, for most cases not far from the value $3.2 \mathrm{hPa} \mathrm{km}^{-1}$ found by Ferlay et al. (2010), suggest that a retrieval of $h$ from $\sigma_{P_{\mathrm{O}_{2}}}$ based on a unique inversion obtained at global scale should lead to better results over ocean than land, and should account for the surface type. This suggests also the robustness and the universality of the statistical relation between $\sigma_{\mathrm{P}_{2}}$ and $H$. However, to go further, it is important to account for the dependence of this relation on other scene parameters.

\subsection{Angular and cloud optical thickness dependences}

The two previous subsections showed the spatial and temporal characteristics of the correlation between the cloud geometrical extent and the angular standard deviation of the oxygen pressure. This explains why the previous study of Ferlay et al. (2010) leads to an acceptable technique of inversion for the ensemble mean of $h$. However, previous simulations and results of Sect. 4 have shown the influence of cloud optical thickness and solar zenith angle on cloud oxygen pressure. These parameters affect also the relation between $\sigma_{P_{\mathrm{O}_{2}}}$ and CPR/CALIOP $H$, and this dependence has to be accounted for to reach the goal of an improved retrieval of $h$ from oxygen A-band measurements.

Figure 11 shows the amplitude of this dependence and the complexity of the relation between $\sigma_{P_{\mathrm{O}_{2}}}$ and $H$ for monolayered liquid water clouds in 2008 over ocean: for a given value of $\sigma_{\mathrm{P}_{2}}$, several values of $H$ are observed on average for various classes of cosine of solar zenith angle $\mu_{\mathrm{s}}$ and cloud optical thickness $\tau$. For example, an optically thin cloud with small vertical extent will lead to the same $\sigma_{P_{\mathrm{O}_{2}}}$ as an optically 


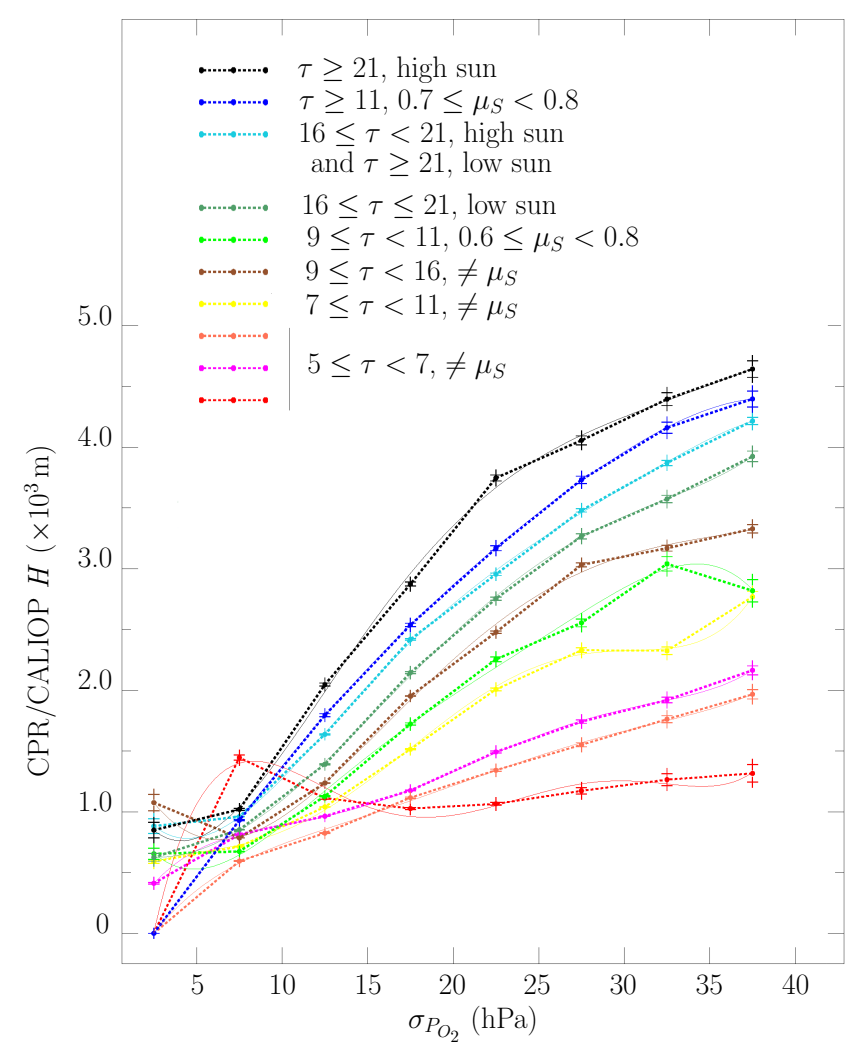

Fig. 11. Average relation $\left(H, \sigma_{P_{\mathrm{O}_{2}}}\right)$ and fifth-order fits by classes of $\tau$ and $\mu_{\mathrm{s}}$. Cases of monolayered liquid clouds in 2008 over ocean, with $\tau \geq 5$ and $c c \geq 0.95$

thick cloud with large vertical extent. In order to better retrieve $h$ from $\sigma_{P_{\mathrm{O}_{2}}}$, we built parameterizations taking into account the cloud optical thickness $\tau$ and the cosine of the solar zenith angle $\mu_{\mathrm{s}}$. We sorted cloudy pixels into 10 classes over ocean (as illustrated in Fig. 11) and six over continents. Fits of fifth order were obtained that provide the set of coefficients linking $\sigma_{P_{\mathrm{O}_{2}}}$ to $H$ for each $\left(\mu_{\mathrm{s}}, \tau\right)$ classes. Results from the $\left(H-\sigma_{\mathrm{O}_{2}}\right)$ fits are discussed in Sect. 6.

\section{Information about cloud vertical extent: synthesis}

We have described two ways to retrieve cloud vertical extent from POLDER3 data. The first one takes advantage of the estimates of cloud pressures described in Sect. 4. Indeed, cloud top and middle oxygen pressures (CTOP and CMOP) can be converted to altitudes, and their difference provides in principle half of the cloud vertical extent. This method is applied here for both liquid and ice clouds. The second method takes advantage of the correlation between the angular standard deviation of the oxygen pressure $\sigma_{\mathrm{P}_{2}}$ and the cloud geometrical thickness $h$. As described in Sect. 5.3, a $\left(\mu_{\mathrm{s}}, \tau\right)$ parameterization makes possible the retrieval of $h$ from $\sigma_{\mathrm{O}_{2}}$.

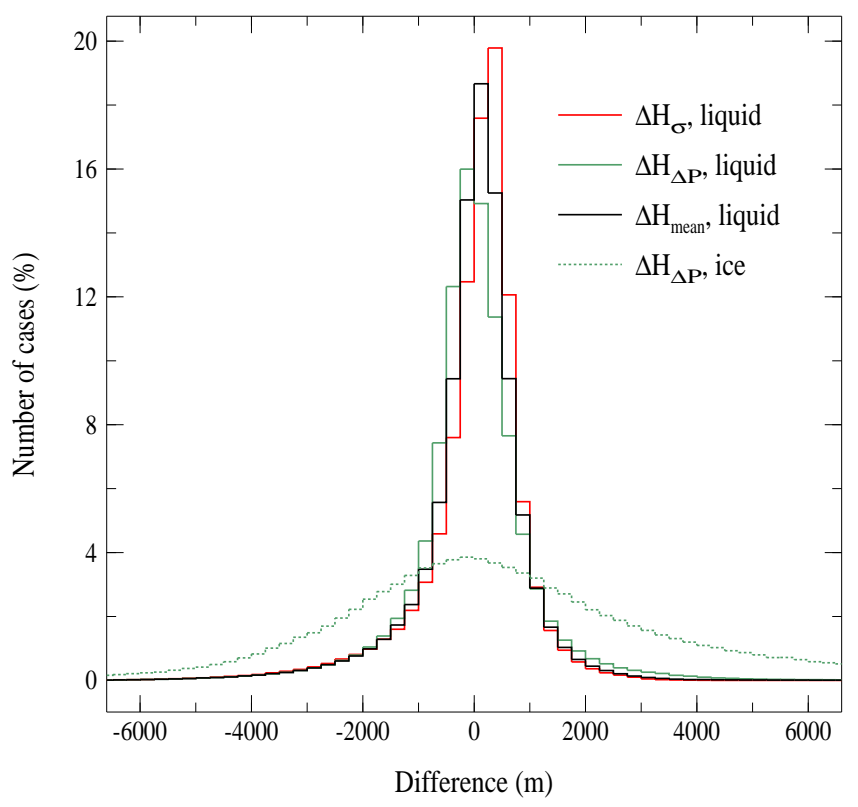

Fig. 12. Histogram of the difference between the CPR/CALIOP $H$ and the retrieved $h$ for liquid water clouds (solid line) and ice clouds (dashed line) over ocean in 2008. For the red curve (green), $h$ was retrieved from $\sigma_{\mathrm{P}_{2}}$ (from $\Delta P$ ). For liquid water clouds, the black curve shows the difference between the mean retrieval $H_{\text {mean }}$ and $H$ (see text for explanation).

At the present time, this second method is only applied to liquid water clouds.

In the following, we will denote by $H_{\Delta P}$ the vertical extent retrieved from the difference of pressures, and by $H_{\sigma}$ the vertical extent retrieved from $\sigma_{P_{\mathrm{O}_{2}}}$. For liquid water cloudy pixels, $H_{\text {mean }}$ stands for the average of $H_{\Delta P}$ and $H_{\sigma}$.

Figure 12 shows the histograms of the difference between CPR/CALIOP $H$ and the POLDER retrieved $H_{\triangle P}$ and $H_{\sigma}$ for clouds over ocean in 2008.

For liquid water clouds, the histogram of $\Delta H_{\sigma}=H_{\sigma}$ $H$ is almost centered on zero: $\overline{\Delta H_{\sigma}}=5 \mathrm{~m}$ with a standard deviation $\mathrm{SD}=964 \mathrm{~m}$ and a median $\mathrm{MD}=180 \mathrm{~m}$. The histogram of $\Delta H_{\Delta P}=H_{\triangle P}-H$ is slightly offcentered: $\overline{\Delta H_{\Delta P}}=-12 \mathrm{~m}, \mathrm{SD}=1193 \mathrm{~m}$, but the median is lower $(\mathrm{MD}=-21 \mathrm{~m})$. For $\Delta H_{\text {mean }}, \overline{\Delta H_{\text {mean }}}=-17 \mathrm{~m}$, $\mathrm{SD}=983 \mathrm{~m}$, and $\mathrm{MD}=73 \mathrm{~m}$, which shows that the vertical extents retrieved by the two methods are consistent pixel by pixel. Results are summarized in Table 2.

For liquid clouds over land, histograms are not shown here but characteristics of the estimates are also given in Table 2. The averages of the differences are quite different: $\overline{\Delta H_{\sigma}}=23 \mathrm{~m}$ and $\overline{\Delta H_{\Delta P}}=-272 \mathrm{~m}$. Defining an average estimate $H_{\text {mean }}$ appears in such case not very relevant as $\overline{\Delta H_{\text {mean }}}$ equals $-138 \mathrm{~m}$, deviating much more from zero than $\Delta H_{\sigma}$. For ice clouds over ocean, $\overline{\Delta H_{\Delta P}}=1580 \mathrm{~m}$ with $\mathrm{SD}=5803 \mathrm{~m}$ and $\mathrm{MD}=-26 \mathrm{~m}$. These values are very high compared with liquid clouds, but ice clouds have generally a 


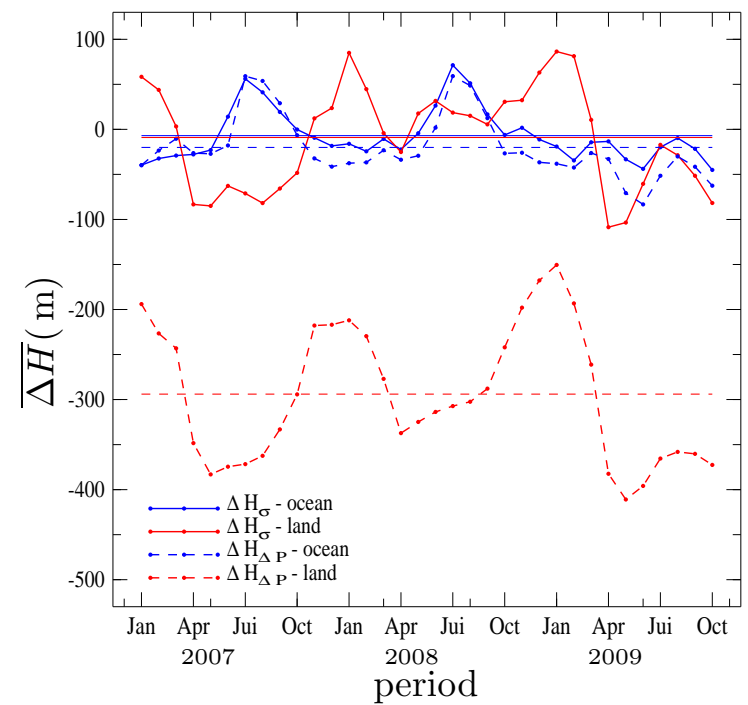

(a) Liquid water clouds

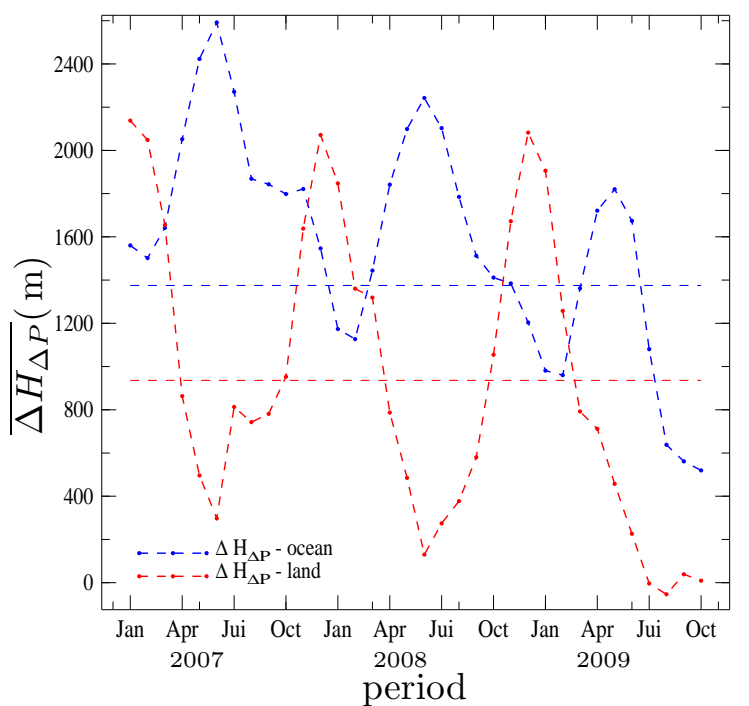

(b) Ice clouds

Fig. 13. Temporal evolution of the monthly average difference between CPR/CALIOP $H$ and the POLDER retrieved $H_{\triangle P}$ and $H_{\sigma}$ from 2007 to 2009 for liquid water clouds (a) and ice clouds (b). Solid lines are for $\Delta H_{\sigma}=H_{\sigma}-H$, and dashed lines for $\Delta H_{\Delta P}=H_{\Delta p}-H$ : in blue over ocean, and red over land. The standard deviation is not represented as it stays close to $1000 \mathrm{~m}$ (5000 m) for liquid (ice) clouds all along the three years.

Table 2. Statistics of the retrieval of cloud geometrical $H_{2}$ thickness for liquid water and ice clouds in 2008 over ocean and land. $\Delta H=$ $H_{\text {retrieved }}-H$ for the different methods of retrieval. SD (MD) stands for standard deviation (median). All values are in meters.

\begin{tabular}{|c|c|c|c|c|c|c|}
\hline \multirow[b]{3}{*}{ Method } & \multicolumn{6}{|c|}{ Liquid water clouds } \\
\hline & \multicolumn{3}{|c|}{ Ocean } & \multicolumn{3}{|c|}{ Land } \\
\hline & $\Delta H$ & SD & MD & $\Delta H$ & $\mathrm{SD}$ & MD \\
\hline$\sigma_{P_{\mathrm{O}_{2}}}$ & 5 & 964 & 180 & 23 & 1146 & 300 \\
\hline$\Delta P$ & -12 & 1193 & -21 & -272 & 1425 & -202 \\
\hline \multirow[t]{3}{*}{ Mean } & -17 & 983 & 73 & -138 & 1186 & 61 \\
\hline & \multicolumn{6}{|c|}{ Ice clouds } \\
\hline & \multicolumn{3}{|c|}{ Ocean } & \multicolumn{3}{|c|}{ Land } \\
\hline Method & $\Delta H$ & SD & MD & $\Delta H$ & SD & MD \\
\hline$\Delta P$ & 1580 & 5803 & -26 & 857 & 4859 & -227 \\
\hline
\end{tabular}

much larger vertical extent than liquid water clouds and consequently the difference are relatively less important compared to the ice cloud vertical extents. For ice clouds over land, histogram of $\Delta H_{\Delta P}$ is sharper than over ocean. This is partly due to the cloud population, which contains more clouds with vertical extent below $7000 \mathrm{~m}$ and less clouds with $h$ above $10000 \mathrm{~m}$ (see Fig. 4).

Figure 12 shows the annual difference $\Delta H$ between the retrieved cloud vertical extents from POLDER and CPR/CALIOP over the year 2008. In order to analyze the robustness of our retrieval, we studied the temporal evolution of the monthly mean of $\Delta H$. Figure 13 shows the mean differences of $\Delta H_{\sigma}$ (solid lines) and $\Delta H_{\Delta P}$ (dashed lines)

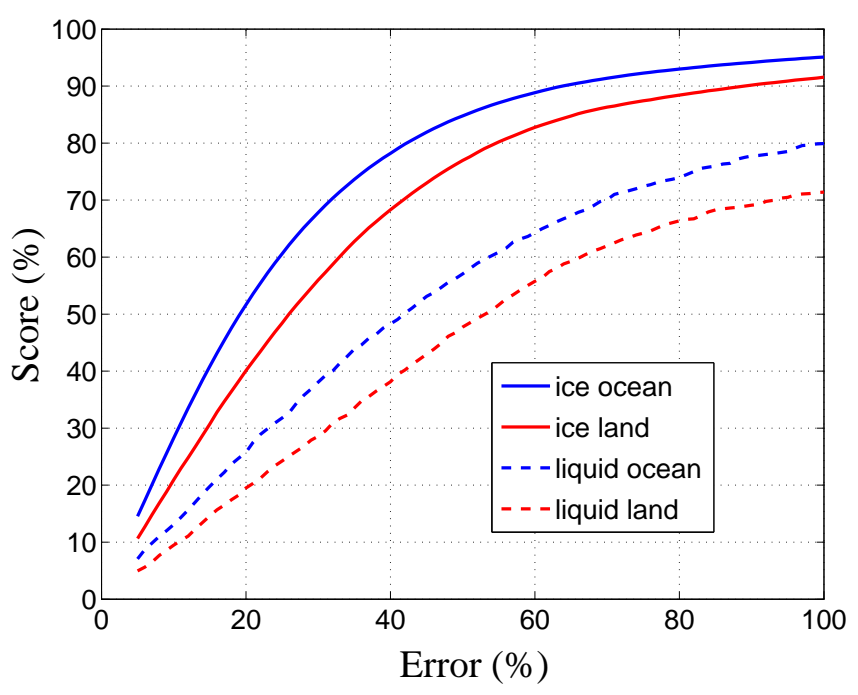

Fig. 14. Scores obtained in 2008 by the POLDER estimate of cloud vertical extent for liquid water (dashed line) and ice clouds (solid line) as a function of the retrieval error in percent. Scores correspond to a confidence in the retrieval for a given error. Scores are global (all classes of cloud geometrical thickness).

month by month from 2007 to 2009 above land (red curves) and ocean (blue curves).

For liquid water clouds (Fig. 13a), the monthly mean $\overline{\Delta H_{\sigma}}$ is low over the three years over ocean and land, with values between $-100 \mathrm{~m}$ and $+100 \mathrm{~m}$. Averages are $-7 \mathrm{~m}$ and $-9 \mathrm{~m}$ over ocean and land, respectively, and the standard deviation 


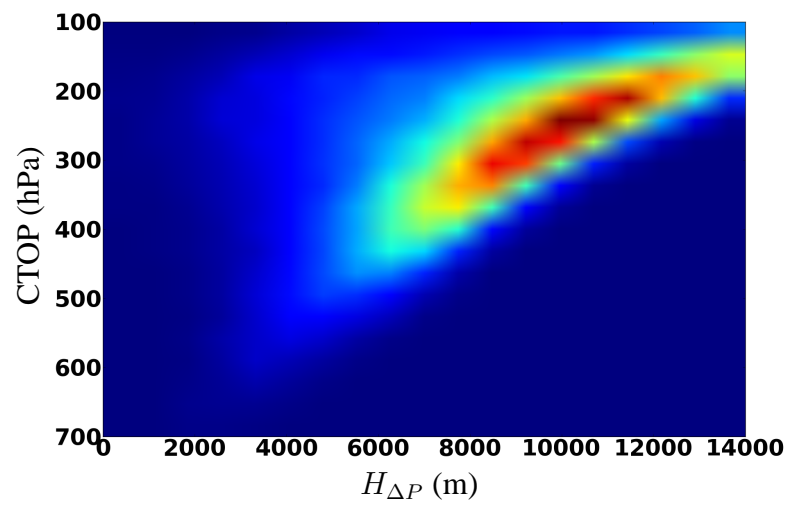

(a) Ice clouds over ocean

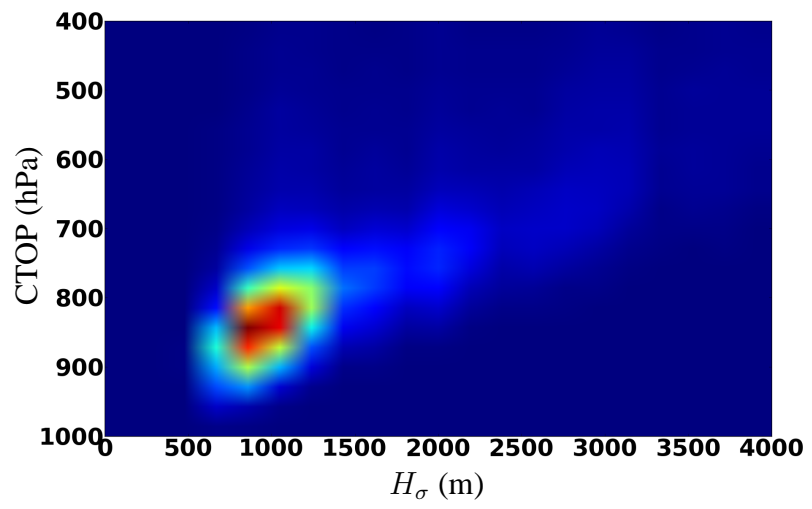

(b) Liquid clouds over ocean

Fig. 15. POLDER-based climatology of cloud top pressure versus cloud vertical extent for selected monolayered clouds in 2008: ice clouds (a) and liquid clouds (b) over ocean. To be compared with the left-hand panels of Fig. 4.

is close to $1000 \mathrm{~m}$ whatever the surface. During the same period, the monthly mean $\overline{\Delta H_{\Delta P}}$ is low over ocean with values between $-100 \mathrm{~m}$ and $+100 \mathrm{~m}$ but further away from zero over land, where the values range from $-200 \mathrm{~m}$ to $-400 \mathrm{~m}$. The averages are $-20 \mathrm{~m}$ over ocean and $-294 \mathrm{~m}$ over land and the standard deviation is higher $(1500 \mathrm{~m})$ over land than over ocean $(1100 \mathrm{~m})$. These observations are consistent with Fig. 12. In the case of liquid clouds over land, the lower performance of $H_{\triangle P}$ can be explained by the bias in the inference of CMP and CTP for low-level clouds mentioned in Sect. 4.2. Low-level clouds represent indeed the majority of liquid clouds. For ice clouds (Fig. 13b), differences observed over 2008 are also observed month by month: they are higher compared with liquid clouds, $\overline{\Delta H_{\triangle P}}=1375 \mathrm{~m}$ above ocean, and $\overline{\Delta H_{\Delta P}}=936 \mathrm{~m}$ above land. The standard deviation is almost the same during the three years, and whatever the surface, it is close to $5000 \mathrm{~m}$. However, contrary to what we observe for liquid clouds, there is no important difference in the performance of $H_{\Delta P}$ over ocean and land. This could be explained by the fact that surface effects are smaller in the case of ice clouds (clouds are on average thicker and at higher altitudes). There is a clear trend in the difference for ice clouds, with higher values in 2007 down to lower values in 2009. This trend is questionable. It might be due to the fact that the parameterization for retrieving $h$ was learned in 2008, and applied over 2007 and 2009. Although not shown here, we observe also that, while the CPR/CALIOP monthly mean of $H$ for ice clouds is stable over three years, the one we retrieve decreases slightly.

This first analysis of the biases of cloud vertical extent estimates leads to the choice of $H_{\sigma}$ as estimate of $h$ for liquid water clouds, while for ice clouds, $h$ is estimated by $H_{\Delta P}$. A further analysis of the POLDER estimates of the liquid water cloud vertical extents shows an overestimation of $h$ for some of the thinnest clouds, and an underestimation for some of the thickest. These tendencies are not surprising considering the physical principle of the retrieval. For ice clouds, the verti- cal extent of the thickest clouds (more than $12 \mathrm{~km}$ ) are either underestimated or overestimated, as for some of the thinnest ice clouds.

As for cloud top pressure estimates, we computed the score obtained by the POLDER estimate of $h$. It is defined as the occurrence of $h$ estimates less than a given percentage away from the actual value $H$ given by CPR/CALIOP. The score corresponds thus to the confidence in the cloud vertical extent's retrieval for a given accuracy. Global scores for all classes of $H$ are shown in Fig. 14 for liquid water and ice clouds and for different accuracies between 5 and $100 \%$. Scores are higher for ice clouds. The fact that the geometrical thickness of ice clouds is often much larger than the one of liquid water clouds mostly explains this difference. Scores are also lower over land. Figure 14 shows for example that scores obtained by the POLDER estimate of $h$ are, for a $30 \%$ retrieval error, of around 70, 60, 40 and $30 \%$ for, respectively, ice clouds over ocean and over land, and liquid water clouds over ocean and over land. Alternatively, Fig. 14 shows that scores equal to $50 \%$ come with a retrieval error of $20,26,42$ and $53 \%$ for the same cases.

\section{Conclusions}

The perspective of retrieving the vertical location of cloud cover, i.e., both their top altitudes (or pressure) and their vertical extents from satellite passive measurements, is challenging and would be very interesting for a broad range of applications in atmospheric sciences. Ferlay et al. (2010) showed the potential of POLDER oxygen A-band measurements for reaching this goal. Pathlength within clouds of solar-reflected photons varies with the viewing zenith angle, and so does, consequently, their absorption by oxygen. This leads to an angular variation of POLDER oxygen pressure, quantified by its angular standard deviation $\sigma_{\mathrm{P}_{2}}$, which is correlated with the cloud geometrical thickness. 
In the present study, we confirm this potential of POLDER measurements with a more detailed study of the complex relation between POLDER oxygen parameters, actual cloud pressures, and vertical extent. We use for this the richness of the collocated and quasi-simultaneous observations from POLDER3 on PARASOL and the active sensors CPR/CloudSat and CALIOP/CALIPSO over multiple years.

We show here the possibility of providing a cloud top oxygen pressure (CTOP) and a cloud middle oxygen pressure (CMOP), which are relatively good estimates of actual top and middle pressures of monolayer clouds. These two new pressures are obtained from parameterizations that are $\left(\mu_{\mathrm{s}}, \tau\right)$ dependent, with $\mu_{\mathrm{s}}$ the cosine of the solar zenith angle and $\tau$ the cloud optical thickness. The performance of these retrievals is presented by classes of ISCCP clouds. For clouds with a high vertical extent (deep convective clouds, cirrostratus, or altostratus), the results are spectacular as CTOP appears much closer to the actual CTP than $P_{\mathrm{O}_{2}}$. For low-level liquid clouds $(\mathrm{CTP}>680 \mathrm{hPa}$ ), POLDER retrieval tends to slightly underestimate the actual cloud top and middle pressures. But the scores obtained by POLDER cloud top pressure estimates are good and high where cloud population is the highest. They reach $60 \%$ considering a retrieval error of plus or minus $30 \mathrm{hPa}$ and $50 \mathrm{hPa}$ for liquid and ice clouds, respectively. Global scores are higher for liquid clouds compared with ice clouds for a given pressure error. Said differently, the same score comes with a higher uncertainty on the cloud top pressure estimate of ice clouds. Because the vertical variation of the atmospheric pressure is much faster at low altitude compared with high altitude, the same confidence score comes with a much higher uncertainty on the cloud top altitude estimate of high level clouds, mostly iced.

From the difference between CMOP and CTOP, one can provide in principle a first estimate of the cloud vertical extent $h, H_{\Delta P}$, although $H_{\Delta P}$ may suffer from the addition of the retrieval biases of CMOP and CTOP. A second estimate $H_{\sigma}$ is obtained directly from the correlation between $\sigma_{P_{\mathrm{O}_{2}}}$ and $H$. This correlation is shown to be complex, but also spatially and temporally robust for liquid water clouds, particularly over ocean. The study of this correlation lead us to establish $\left(\mu_{\mathrm{s}}, \tau\right)$ parameterizations for liquid water clouds over ocean and over land, which allow for the retrieval of $h$ from $\sigma_{P_{\mathrm{O}_{2}}}$. Thus, we obtain two estimates of $h, H_{\Delta P}$, and $H_{\sigma}$ for liquid clouds. Over ocean, we show that the two estimates are consistent at the pixel level with close performances. Over land, $H_{\Delta P}$ underestimates slightly on average the retrieval of $h$. For ice clouds, the vertical extent of clouds are estimated with $H_{\Delta P}$ only. For these clouds, the differences are on average much larger in absolute value compared with the liquid case, but the relative differences are lower.

The POLDER estimates of cloud vertical extent shown here are new, and the results given here are, in a way, preliminary. The vertical extent of thin (thick) liquid water clouds tends to be overestimated (underestimated), while the vertical extent of thick ice clouds tends to be underestimated.
The case of ice clouds is more complex to handle, and so far, their vertical extent has not been obtained from $\sigma_{P_{\mathrm{O}_{2}}}$ but from CMOP and CTOP. This is certainly due to their more complex and heterogeneous microphysics. Despite the limits of our current retrieval, we obtain confidence scores for cloud top pressure and geometrical thickness estimates that are good and yet high for some cases. With CTOP and our estimate of $h, \mathrm{CTP}-h$ diagrams can be produced. Figure 15 shows such an inferred climatological diagram for ice and liquid clouds over ocean. The comparison with the "true" one on the left-hand panels of Fig. 4 shows that some features of the climatology are obtained: for ice clouds, the bow shape tendency is visible, though much more scattered; for liquid clouds, the main mode of the 2-D distribution is present but centered at the abscissa $1000 \mathrm{~m}, 300 \mathrm{~m}$ too high compared with the "true" one.

While preliminary, the results presented in this study are promising and encouraging, since obtaining complete information about cloud vertical location from a passive instrument and at global scale is yet to come and is challenging (Rozanov and Kokhanovsky, 2004). In the future, progress in the understanding of the relation between the cloud vertical extent and the angular variation of POLDER oxygen pressure are expected, particularly for ice clouds. It is also necessary to evaluate the performance of our cloud retrievals outside the CloudSat/CALIPSO track. Lastly, in order to make our retrieval methods operational, an important point is the identification of the mono/multilayer character of cloud cover over the entire POLDER swath. We have some confidence in this distinction's capability from the POLDER measurements, thanks again to the use of its multidirectional character.

Acknowledgements. This study has been financed through grants from the French research CNRS program PNTS (Programme National de Télédétection spatiale) and CNES program TOSCA (Terre, Océan, Surfaces continentales, Atmosphère). We are grateful to the ICARE center (http://www.icare.univ-lille1.fr/) for providing easy access to CALIPSO-collocated PARASOL, CloudSat, and MODIS data (MULTI_SENSOR products), as well as computing resources.

Edited by: O. Dubovik

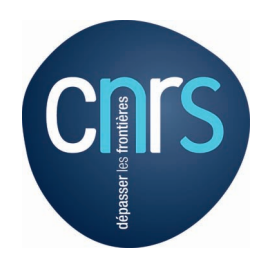

The publication of this article is financed by CNRS-INSU. 


\section{References}

Bloom, S., da Silva, A., and Dee, D.: Documentation and validation of the Goddard Earth Observing System (GEOS) Data Assimilation System-Version 4, Tech. Rep., 165 pp., Series on Global Modeling and Data Assimilation, NASA Tech. Memo. NASA/TM-2005-104606, 2005.

Buriez, J., Vanbauce, C., Parol, F., Goloub, P., Herman, M., Bonnel, B., Fouquart, Y., Couvert, P., and Sèze, G.: Cloud detection and derivation of cloud properties from POLDER, Int. J. Remote. Sens., 18, 2785-2813, 1997.

Ferlay, N., Thieuleux, F., Cornet, C., Davis, A. B., Dubuisson, P., Ducos, F., Parol, F., Riédi, J., and Vanbauce, C.: Toward New Inferences about Cloud Structures from Multidirectional Measurements in the Oxygen A Band: Middle-of-Cloud Pressure and Cloud Geometrical Thickness from POLDER-3/PARASOL, J. Appl. Meteorol. Clim., 49, 2492-2507, 2010.

Fischer, J. and Grassl, H.: Detection of Cloud-Top-Height from Backscattered Radiances within the Oxygen A Band. Part 1: Theoretical Study, J. Appl. Meteorol., 30, 1245-1259, 1991.

Fischer, J., Cordes, W., Schmitz-Peiffer, A., Renger, W., and Mörl, P.: Detection of Cloud-Top-Height from Backscattered Radiances within the Oxygen A Band. Part 2: measurements, J. Appl. Meteorol., 30, 1260-1267, 1991.

Fournier, N., Stammes, P., de Graaf, M., van der A, R., Piters, A., Grzegorski, M., and Kokhanovsky, A.: Improving cloud information over deserts from SCIAMACHY Oxygen A-band measurements, Atmos. Chem. Phys., 6, 163-172, doi:10.5194/acp-6163-2006, 2006.

Goloub, P., Deuze, J. L., Herman, M., and Fouquart, Y.: Analysis of the POLDER polarization measurements performed over cloud covers, IEEE T. Geosci. Remote Sens., 32, 78-88, 1994.

Holz, R. E., Ackerman, S. A., Nagle, F. W., Frey, R., Dutcher, S., Kuehn, R. E., Vaughan, M. A., and Baum, B.: Global Moderate Resolution Imaging Spectroradiometer (MODIS) cloud detection and height evaluation using CALIOP, J. Geophys. Res., 113, D00A19, doi:10.1029/2008JD009837, 2008.

Knibbe, W. J. J., de Haan, J. F., Hovenier, J. W., Stam, D. M., Koelemeijer, R. B. A., and Stammes, P.: Deriving terrestrial cloud top pressure from photopolarimetry of reflected light, J. Quant. Spectrosc. Ra. , 64, 173-199, 2000.

Koelemeijer, R. B. A., Stammes, P., Hovenier, J. W., and de Haan, J. F.: A fast method for retrieval of cloud parameters using oxygen A band measurements from GOME, J. Geophys. Res., 106, 3475-3490, 2001.

Kuze, A. and Chance, K. V.: Analysis of cloud top height and cloud coverage from satellites using the $\mathrm{O}_{2} \mathrm{~A}$ and $\mathrm{B}$ bands, J. Geophys. Res., 99, 14481-14,492, 1994.

Lelli, L., Kokhanovsky, A. A., Rozanov, V. V., Vountas, M., Sayer, A. M., and Burrows, J. P.: Seven years of global retrieval of cloud properties using space-borne data of GOME, Atmos. Meas. Tech., 5, 1551-1570, doi:10.5194/amt-5-1551-2012, 2012.

Lindstrot, R., Preusker, R., Ruhtz, T., Heese, B., Wiegner, M., Lindemann, C., and Fischer, J.: Validation of MERIS cloud top pressure using airborne lidar measurements, J. Appl. Meteorol. Clim., 45, 1612-1621, 2006.

Mace, G. G., Zhang, Q., Vaughan, M., Marchand, R., Stephens, G., Trepte, C., and Winker, D.: A description of hydrometeor layer occurrence statistics derived from the first year of merged Cloudsat and CALIPSO data, J. Geophys. Res., 114, D00A26,
doi:10.1029/2007JD009755, 2009.

Menzel, W. P., Frey, R. A., Zhang, H., Wylie, D. P., Moeller, C. C., Holz, R. E., Maddux, B., Baum, B. A., Strabala, K. I., and Gumley, L. E.: MODIS Global Cloud-Top Pressure and Amount Estimation: Algorithm Description and Results, J. Appl. Meteorol. Clim., 47, 1175-1198, 2008.

Parol, F., Buriez, J.-C., Vanbauce, C., Couvert, P., Séze, G., Goloub, P., and Cheinet, S.: First results of the POLDER"Earth Radiation Budget and Clouds" operational algorithm, IEEE T. Geosci. Remote Sens., 37, 1597-1612, 1999.

Press, W. H., Teukolsky, S. A., Vetterling, W. T., and Flannery., B. P.: numerical Recipes in Fortran 77: The Art of Scientific Computing, 2nd Edn., Cambridge University Press, 1992.

Preusker, R. and Lindstrot, R.: Remote Sensing of Cloud-Top Pressure Using Moderately Resolved Measurements within the Oxygen A Band - A Sensitivity Study, J. Appl. Meteorol. Clim., 48, 1562-1574, 2009.

Preusker, R., Fischer, J., P., A., Bennartz, R., and Schüller, L.: Cloud-top pressure retrieval using the oxygen A-band in the IRS3 MOS intrument, Int. J. Remote. Sens., 28, 1957-1967, 2007.

Rossow, W. B. and Schiffer, R. A.: Advances in understanding clouds from ISCCP, B. Am. Meteorol. Soc., 80, 2261-2287, 1999.

Rothman, L. S., Jacquemarta, D., Barbeb, A., Bennerc, D. C., Birkd, M., Browne, L., Carleerf, M., Jr., C. C., Chancea, K., Couderth, L., Danai, V., Devic, V., Flaudh, J.-M., Gamachej, R., Goldmank, A., Hartmannh, J.-M., Jucksl, K., Makim, A., Mandini, J.Y., Massien, S., Orphalh, J., Perrinh, A., Rinslando, C., Smitho, M., Tennysonp, J., Tolchenovp, R., Tothe, R., Auweraf, J. V., Varanasiq, P., and Wagnerd, G.: The HITRAN molecular spectroscopic database, J. Quant. Spectrosc. Ra., 96, 139-204, 2005.

Rozanov, V. V. and Kokhanovsky, A. A.: Semianalytical cloud retrieval algorithm as applied to the cloud top altitude and the cloud geometrical thickness determination from top-of-atmosphere reflectance measurements in the oxygen A band, J. Geophys. Res., 109, D05202, doi:10.1029/2003JD004104, 2004.

Saiedy, F., Hilleary, D. T., and Morgan, W. A.: Cloud-top altitude measurements from satellites, Appl. Optics, 4, 495-500, 1965.

Scott, N.: A direct method of computation of transmission function of an inhomogeneous gaseous medium: description of the method and influence of various factors, J. Quant. Spectrosc. Ra., 14, 691-707, 1974.

Seiz, G., Tjemkes, S., and Watts, P.: Multiview cloud-top height and wind retrieval with photogrammetric methods: Application to Meteosat-8 HRV observations, J. Appl. Meteor. Climatol., 46, 1182-1195, 2007.

Sneep, M., de Haan, J. F., Stammes, P., Wang, P., Vanbauce, C., Vasilkov, A. P., and Levelt, P. F.: Three-way comparison between OMI and PARASOL cloud pressure products, J. Geophys. Res., 113, D15S23, doi:10.1029/2007JD008694, 2008.

Stephens, G. L.: Radiation profiles in extended water clouds. I: Theory, J. Atmos. Sci., 35, 2111-2122, 1978.

Stephens, G. L., Vane, D. G., Boain, R. J., Mace, G. G., Sassen, K., Wang, Z., Illingworth, A. J., O'Connor, E. J., Rossow, W. B., Durden, S. L., Miller, S. D., Austin, R. T., Benedetti, A., Mitrescu, C., and Team, T. C. S.: The CloudSat mission and the A Train, A New Dimension of Space-Based Observations of Clouds and Precipitation, B. Amer. Meteorol. Soc., 83, 17711790, 2002. 
Stubenrauch, C. J., Chédin, A., Rädel, G., Scott, N. A., and Serrar, S.: Cloud Properties and Their Seasonal and Diurnal Variability from TOVS Path-B, J. Climate, 19, 5531-5553, 2006.

Vanbauce, C., Buriez, J., Parol, F., Bonnel, B., Seze, G., and Couvert, P.: Apparent pressure derived from ADEOS-POLDER observations in the oxygen A-band over ocean, Geophys. Res. Lett., 25, 3159-3162, 1998.

Vanbauce, C., Cadet, B., and Marchand, R.: Comparison of POLDER apparent and corrected oxygen pressure to ARM/MMCR cloud boundary pressures, Geophys. Res. Lett., 30, 16.1-16.4, 2003.

van de Hulst, H. C.: Multiple Light Scattering, Tables, Formulas and Applications, Volume 2, Academic Press, 1980.

Wang, J. and Rossow, W. B.: Effects of cloud vertical structure on atmospheric circulation in the GISS GCM, J. Climate, 12, 30103029, 1998.

Wang, J., Rossow, W., and Zhang, Y.: Cloud Vertical Structure and Its Variations from a 20-Yr Global Rawinsonde Dataset, J. Climate, 13, 3041-3056, 2000.

Wang, P., Stammes, P., van der A, R., Pinardi, G., and van Roozendael, M.: FRESCO+: an improved $\mathrm{O}_{2}$ A-band cloud retrieval algorithm for tropospheric trace gas retrievals, Atmos. Chem. Phys., 8, 6565-6576, doi:10.5194/acp-8-6565-2008, 2008.

Warren, S. G., Eastman, R., and Hahn, C. J.: Cloud Climatology. Encyclopedia of Atmospheric Sciences, 2nd Edn., Oxford University Press, 2012.

Weisz, E., Li, J., Zhou, D. K., Huang, H.-L., Goldberg, M. D., and Yang, P.: Cloudy sounding and cloud-top height retrieval from AIRS alone single field-of-view radiance measurements, Geophys. Res. Lett., 34, L12802, doi:10.1029/2007GL030219, 2007.
Wielicki, B. A. and Coakley, J. A.: Cloud retrieval using infrared sounder data: Error analysis, J. Appl. Meteorol., 20, 157-169, 1981.

Winker, D. M. and Trepte, C. R.: Laminar cirrus observed near the tropical tropopause by LITE, Geophys. Res. Lett., 25, 33513354, 1998.

Winker, D. M., Hunt, W. H., and McGill, M. J.: Initial performance assessment of CALIOP, Geophys. Res. Lett., 34, L19803, doi:10.1029/2007GL030135, 2007.

Wu, D. L., Ackerman, S. A., Davies, R., Diner, D. J., Garay, M. J., Kahn, B. H., Maddux, B. C., Moroney, C. M., Stephens, G. L., Veefkind, J. P., and Vaughan, M. A.: Vertical distributions and relationships of cloud occurrence frequency as observed by MISR AIRS, MODIS, OMI, CALIPSO, and CloudSat, Geophys. Res. Lett., 36, L09821, doi:10.1029/2009GL037464, 2009.

Wu, M. L.: Remote Sensing of cloud-top pressure using reflected solar radiation in the oxygen A-band, J. Appl. Meteorol., 24, 539-546, 1985.

Yamamoto, G. and Wark, D. Q.: Discussion of the letter by R. A. Hanel, 'Determination of cloud altitude from a satellite', J. Geophys. Res., 66, 10, 3596-3596, doi:10.1029/JZ066i010p03596, 1961.

Yang, Y., Marshak, A., Mao, J., Lyapustin, A., and Herman, J.: A method of retrieving cloud top height and cloud geometrical thickness with oxygen A and B bands for the Deep Space Climate Observatory (DSCOVR) mission: Radiative transfer simulations, J. Quant. Spectrosc. Ra., 122, 141-149, 2013. 